\title{
Remote sensing the plasmasphere, plasmapause, plumes and other features using ground-based magnetometers
}

\author{
Frederick Menk ${ }^{1, *}$, Zoë Kale ${ }^{2}$, Murray Sciffer ${ }^{1}$, Peter Robinson ${ }^{1}$, Colin Waters ${ }^{1}$, Russell Grew ${ }^{1}$, Mark Clilverd ${ }^{3}$, \\ and Ian Mann ${ }^{2}$ \\ 1 School of Mathematical and Physical Sciences, University of Newcastle, Callaghan, NSW 2308 Australia \\ ${ }^{*}$ Corresponding author: fred.menk@newcastle.edu.au \\ 2 Physics Department, University of Alberta, Edmonton, Alberta T6G2J1, Canada \\ 3 British Antarctic Survey, High Cross, Cambridge CB3 0ET, UK
}

Received 15 April 2014 / Accepted 1 October 2014

\begin{abstract}
The plasmapause is a highly dynamic boundary between different magnetospheric particle populations and convection regimes Some of the most important space weather processes involve wave-particle interactions in this region, but wave properties may also be used to remote sense the plasmasphere and plasmapause, contributing to plasmasphere models. This paper discusses the use of existing ground magnetometer arrays for such remote sensing. Using case studies we illustrate measurement of plasmapause location, shape and movement during storms; refilling of flux tubes within and outside the plasmasphere; storm-time increase in heavy ion concentration near the plasmapause; and detection and mapping of density irregularities near the plasmapause, including drainage plumes, biteouts and bulges. We also use a 2D MHD model of wave propagation through the magnetosphere, incorporating a realistic ionosphere boundary and Alfvén speed profile, to simulate ground array observations of power and cross-phase spectra, hence confirming the signatures of plumes and other density structures.
\end{abstract}

Key words. Magnetosphere (inner) - Plasma waves - Space weather - Monitoring - Density

\section{Introduction}

This paper describes methods and results for remote sensing plasmapause dynamics using existing ground magnetometer arrays. The plasmapause is one of the fundamental magnetospheric boundaries, and separates the dense, cold (eV energy) population of the inner magnetosphere (the plasmasphere) from the low density energized ions and electrons of the outer region. Electric fields drive plasma motion in both regions. In the inner magnetosphere closed streamlines are acted upon by the corotation electric field arising from rotation of the neutral atmosphere and lower ionosphere with Earth. In the outer magnetosphere streamlines map to the magnetopause and tail, and plasma motion is dominated by solar wind induced convection.

The movement of plasma within the plasmasphere and the position of the plasmapause are controlled by several factors. Neutral winds move ionospheric plasma through the geomagnetic field, generating a dynamo electric field and $\mathbf{E} \times \mathbf{B}$ radial drifts of flux tubes. The ionosphere and plasmasphere are in dynamic equilibrium, so field-aligned flux transfer takes place due to pressure differentials arising from diurnal and stormrelated production and loss processes. The refilling rate of depleted flux tubes from the ionosphere can differ for different ion species (Singh \& Horwitz 1992) and the $\mathrm{O}^{+}$concentration may become strongly enhanced near the storm-time plasmapause (Fraser et al. 2005). In addition, the magnetospheric dawn-to-dusk electric field may penetrate to low altitudes and drive cross- $L$ drifts under magnetically disturbed conditions. In fact, the dayside plasmapause responds promptly to over- or under-shielding associated with sudden changes in the convection electric field, and can rapidly develop localized dents, shoulders and other features. Studies with the Cluster spacecraft constellation have shown that density irregularities (depletions of order 20\%; characteristic size $365 \mathrm{~km}$ but up to $5000 \mathrm{~km}$ ) occur frequently within the plasmasphere and at the plasmapause, especially under magnetically active conditions (Darrouzet et al. 2004). Enhanced convection associated with southward turning of the IMF $B_{z}$ also triggers formation of large-scale drainage plumes which allow convective erosion of plasmaspheric plasma to the outer magnetosphere (e.g. Goldstein \& Sandel 2005).

While the plasmapause demarcates different convection regimes, it is also important for other reasons. The ring current arises from the azimuthal motion of trapped particles in the inner magnetosphere and roughly straddles the plasmapause (Darrouzet et al. 2013). The main contributors to the current density are $1-100 \mathrm{keV}$ ions. The quiet time ring current is dominated by protons of both solar wind and ionospheric origin, while $\mathrm{O}^{+}$from the ionosphere becomes increasingly important with increasing geomagnetic activity, dominating the ring current during large storms (Daglis et al. 1999). Ring current particles are lost through collisional processes and pitch angle diffusion by plasma waves, particularly electromagnetic ion-cyclotron (EMIC) waves and magnetosonic whistler mode waves including VLF chorus just outside the plasmasphere, and hiss in plumes and within the plasmasphere (Summers et al. 2007). Favoured regions for EMIC wave occurrence are just inside the dusk plasmapause and in plumes, and particle loss timescales due to EMIC waves depend on the 
plasma ion composition. Furthermore, at storm times electrons may be accelerated to relativistic $(\mathrm{MeV})$ energies by momentum diffusion with chorus waves and wave-particle interactions with $1-10 \mathrm{mHz}$ waves, forming the outer radiation belt straddling the plasmapause. These particles pose space weather hazards. Thus particle populations organized around the plasmapause boundary are important participants in ring current and radiation belt dynamics.

The change in density and hence Alfvén speed at the plasmapause constitutes a boundary for plasma waves propagating in the magnetosphere. This has several consequences. (i) The magnetosphere is separated into outer and inner cavities, able to sustain cavity mode resonances with characteristic periods, amplitude and phase structure. (ii) Field line eigenfrequencies exhibit a sudden change across the plasmapause. (iii) Compressional (fast) mode MHD waves propagating Earthward, on encountering the plasmapause, can mode convert and couple energy to the field guided Alfvén mode. (iv) Wave energy is also reflected at the plasmapause. (v) Surface wave modes and spatially localized guided poloidal mode waves may be excited at or near a steep plasmapause. (vi) The enhanced ion population near the storm-time plasmapause favours the generation of wave-particle instabilities and EMIC waves, as mentioned above, and also affects field line eigenfrequencies. In summary, the plasmapause exerts a profound influence on propagating ULF waves including those involved in wave-particle interactions.

Clearly there are compelling reasons for monitoring and improving knowledge of plasmpause location and spatiotemporal behaviour. To date such information has mostly come from ground-based VLF observations and satellite-borne particle counters, wave experiments and imagers. However, the plasmapause is a highly dynamic three-dimensional structure and these techniques each suffer limitations.

Measurements of VLF whistlers have been used to infer the equatorial electron density and hence the plasmapause position for five decades (e.g. Carpenter 1963; Carpenter \& Park 1973; Park et al. 1978). The whistlers are triggered by lightning and propagate along field-aligned ducts that are most favourably located about $1.5 \mathrm{R}_{\mathrm{E}}$ inside the plasmapause (Walker 1978), so it is difficult to obtain simultaneous observations over a range of $L$ shells. It is widely believed that whistlers are mostly recorded on the ground at night, but detailed analysis of observations from Rothera $(L=2.7)$ shows a preference for winter months with a diurnal maximum near sunrise and occurrence throughout the day (Collier et al. 2011). Whilst better temporal coverage may be achieved using whistler mode signals generated by continuously operating VLF transmitters, the frequencies available restricts this technique to $L \leq 2.7$ (Clilverd et al. 1991).

Satellite-borne particle detectors (e.g. Chappell et al. 1971; Horwitz et al. 1990) and plasma wave instruments (Carpenter \& Anderson 1992; Moldwin et al. 2002) have been used for statistical and case studies of electron density distributions, illustrating the position and evolution of the plasmapause under a range of magnetic conditions. These density profiles can be quite complicated, with regions of detached plasma and other complex structures. The "snapshot" nature of single spacecraft observations makes it difficult to monitor the evolution of such features. Furthermore, spacecraft charging may bias low energy measurements from particle counters.

Using statistical whistler-derived and in situ electron density data, Carpenter and Anderson (1992) developed empirical models describing the electron density profile within the plasmasphere, across the plasmapause and in the outer magnetosphere. The location of the plasmapause inner boundary, $L_{\mathrm{ppi}}$, over 00-15 MLT was given by

$$
L_{\mathrm{ppi}}=5.6-0.46 K p_{\max }
$$

where $K p_{\max }$ is the maximum night-time $K p$ value in the preceding $24 \mathrm{~h}$. In order to better characterize the longitudinal asymmetry in plasmapause shape Moldwin et al. (2002) used linear fits to the entire CRRES in situ plasma wave database to propose a generalized model of the form

$$
L_{\mathrm{ppi}}=\left(A \pm \sigma_{A}\right)+\left(B \pm \sigma_{B}\right) K p
$$

where $A, B, \sigma_{A}$ and $\sigma_{B}$ are parameters that depend on local time. For example, for the 0900-1500 LT sector

$$
L_{\mathrm{ppi}}=(5.20 \pm 0.165)-(0.425 \pm 0.040) K p
$$

and $K p$ is the maximum value over the previous $12 \mathrm{~h}$. Such models assume that $K p$ is related to the strength of convection. Models incorporating local time effects and indices such as Dst and AE associated with specific current systems may be more appropriate predictors of the statistical plasmapause position (O'Brien \& Moldwin 2003).

A wealth of information on the two-dimensional behaviour of the plasmapause has come from observations of the $\mathrm{He}^{+}$distribution by imaging resonantly reflected sunlight at $30.4 \mathrm{~nm}$ using EUV scanners (e.g. Yoshikawa et al. 2000; Goldstein et al. 2002; Sandel et al. 2003). Features observed include semicorotating plumes, radial "fingers" and "voids" of enhanced or depleted density and rapid reconfiguration of the plasmapause boundary in response to changes in the magnetospheric convection electric field. The inferred outward flux of ions suggests the plasmasphere is a significant source of plasma to the outer magnetosphere even under magnetically quiet conditions (Yoshikawa et al. 2000). Unfortunately, such observations are not ongoing and temporal coverage is limited to suitable orbit intervals. Furthermore, the sensitivity of the imagers (equivalent to $30-50$ electrons $\mathrm{cm}^{-3}$ for the IMAGE satellite EUV experiment) means that only relatively dense structures are detected.

Plasma drainage plumes are a particularly important feature of the outer magnetosphere. They comprise elongated structures of dense plasmaspheric plasma typically in the noon to dusk sector during periods of moderate to disturbed geomagnetic activity and persisting well into recovery phases (Spasojević et al. 2003; Moldwin et al. 2004). Plasmaspheric plasma is eroded and lost to the outer magnetosphere through plumes. Irregular internal structures within plumes are likely growth regions for EMIC waves (Morley et al. 2009). Comparison of high resolution in situ measurements from the Cluster spacecraft with IMAGE EUV observations has provided detailed information on plume structure and motion (e.g. Darrouzet et al. 2006).

Measurements of ULF field line resonances (FLRs) with ground-based magnetometers can be used to estimate the equatorial mass density and can therefore complement and extend whistler and spacecraft studies of the plasmapause region (e.g. Menk et al. 1999, 2004; Chi et al. 2000, 2013). The resonances may be observed for many hours during local daytime, so with suitable ground arrays coverage can span a range of latitudes and longitudes. Algorithms have been developed for automated detection of FLRs and determination of mass density (Berube et al. 2003; Lichtenberger et al. 2013), achieving detection rates of order 50\% (Chi et al. 2013). Furthermore, 
comparison of FLR-based mass density estimates with whistler or in situ electron density data (and EUV-derived $\mathrm{He}^{+}$data if available) allows intercalibration of techniques (Clilverd et al. 2003) and provides information on the heavy ion concentration (Berube et al. 2005; Grew et al. 2007). A plasmaspheric mass density model based on extensive observations from 7 ground magnetometer stations near $80^{\circ} \mathrm{W}$ geographic longitude was described by Berube et al. (2005). Averaged over all conditions this model gives

$$
\rho_{\text {eq }}(L)=10^{-0.67 L+5.1} \text {. }
$$

Ozhogin et al. (2012) presented a similar electron density model which also described the field-aligned density variation. Limitations of the FLR technique include the choice of fieldaligned density and magnetic field models (Berube et al. 2006; Takahashi et al. 2006; Vellante \& Föster 2006), experimental uncertainty in determining resonant frequencies, and the lack of FLR observations at night.

It is also possible to estimate the plasma mass density from in situ measurements of the field line eigenfrequency, and comparison with in situ electron density data provides information on the ion mass. A statistical study of the plasmatrough region during solar maximum found the average ion mass is $3.0 \mathrm{amu}$ but increases with increasing geomagnetic activity (Takahashi et al. 2006). Detailed analysis of FLRs and particle measurements in the outer magnetosphere with the Cluster spacecraft can provide information on the density distribution with sufficient precision that uncertainty in frequency is small (Denton et al. 2009).

Comparison of FLR-derived plasmaspheric mass densities with in situ electron density measurements shows that the average ion mass within the plasmasphere is $1-2$ amu at quiet times but increases with proximity to the plasmapause at disturbed times (Berube et al. 2005). Such heavy ion mass loading may distort or mask the appearance of features such as the outer boundary of the plasmapause or plasma plumes when compared with in situ electron density measurements (Fraser et al. 2005; Takahashi et al. 2008). However, the detection of plasma drainage plumes through comparison of ground-based FLR measurements of mass density with EUV images of $\mathrm{He}^{+}$intensity was reported by Abe et al. (2006) and Grew et al. (2007).

According to Kim et al. (2007) plasma mass density (determined with ground magnetometers) does not change deep within the plasmasphere during a magnetic storm and plume event, and sunward plasma erosion via the plume is confined to the outer layers of the plasmasphere.

It is important to realize that the plasmapause and drainage plumes are three-dimensional structures. The high-altitude plasmapause maps to the equatorward edge of the mid-latitude ionospheric trough (Foster et al. 1978; Yizengaw \& Moldwin 2005). Enhanced storm-time density structures are monitored by GPS total electron content (TEC) techniques and incoherent scatter radars and are the low altitude signatures of drainage plumes (Foster et al. 2002; Yizengaw et al. 2008).

This paper illustrates the use of ground-based measurements of ULF FLRs to detect and monitor changes in plasmaspheric density and the plasmapause. This is done through case studies including comparison with satellite particle, imaging and TEC observations and numerical modelling of plasma wave propagation through the magnetosphere. Whilst ground magnetometer measurements alone cannot provide a comprehensive picture of the evolution of plasma features, the existence of multiple ground arrays facilitates their use as a

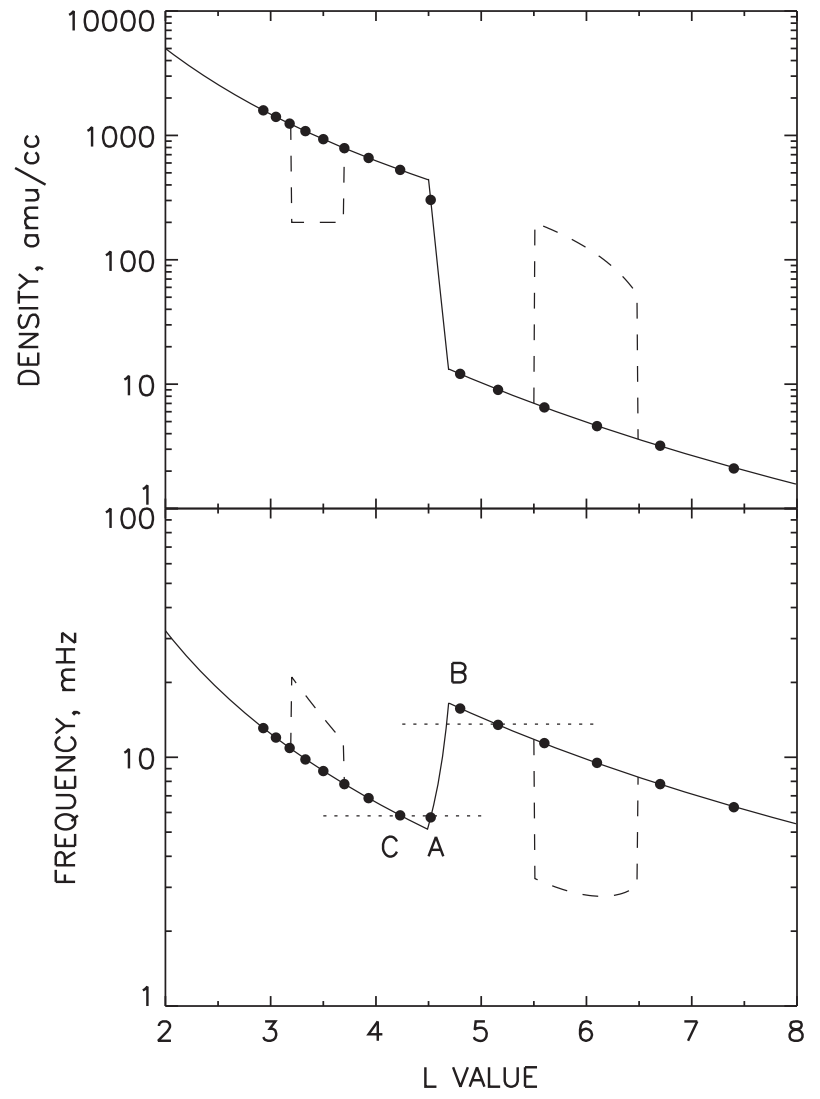

Fig. 1. Model equatorial mass density profile (top) and corresponding radial variation in toroidal mode resonance frequency (bottom). Filled circles represent projection of ground stations separated by $110 \mathrm{~km}$ in geographic latitude, with A, B and C straddling the plasmapause (see text). Dashed lines depict a plasmaspheric density trough or biteout and a hypothesized plasma drainage plume.

monitoring tool and can provide input to suitable models of magnetospheric density and structure.

\section{Techniques}

\subsection{Field line resonances}

The principles behind the measurement of FLRs using ground magnetometers are straightforward and were described in Menk et al. (1999), Waters et al. (2000, 2006) and Menk \& Waters (2013). It is assumed that a spectrum of fast mode ULF plasma waves within the magnetosphere couples energy to local toroidal mode standing field line eigenoscillations. The techniques are based upon identifying the changes in amplitude and phase across a resonance, best accomplished by comparing measurements between a pair of magnetometers closely spaced in latitude. This is illustrated in Figure 1. The top panel shows an idealized equatorial mass density profile based on models described by Poulter \& Allan (1986) and Carpenter \& Anderson (1992). Density within the plasmasphere and plasmatrough falls off with radial distance as $R^{-4}$, the inner boundary of the plasmapause is at $4.5 \mathrm{R}_{\mathrm{E}}$ and the plasmapause width is $0.2 \mathrm{R}_{\mathrm{E}}$. A similar $L$-dependence in mass density was observed by Chi et al. (2013), while equatorial electron densities exhibit an $L^{-3.07}$ dependence (Ozhogin et al. 2012). Filled circles represent the projection to the equatorial plane of stations in a hypothetical ground magnetometer array separated 
by $110 \mathrm{~km}$ in geographic latitude. This is about the optimum station separation for detecting resonance signatures (Menk et al. 2004; see also discussion by Chi et al. 2013). The dashed lines represent a plasmaspheric density trough or biteout of the form described by Carpenter et al. (2000) and a slice through a hypothesized plasma drainage plume.

The bottom panel of Figure 1 shows the corresponding toroidal mode field line eigenfrequency profile. The smooth change in resonance frequency within the plasmasphere and plasmatrough is readily detected as a zero crossing in the amplitude difference and a peak in cross-phase between adjacent magnetometer stations (Waters et al. 1991). A plasmaspheric biteout and drainage plume of the form shown will produce distinct changes in resonant frequency that should, in principle, be easily detectable.

If the equatorial mass density varies with radial distance following an inverse power law $R^{-\alpha}$ then for $\alpha \leq 8$ the toroidal mode field line eigenfrequency decreases with increasing $L$. This is the usual case in the plasmasphere and plasmatrough and results in a particular direction for the cross-phase peak identified at the resonant frequency between two adjacent magnetometers.

However, if at a steep density gradient $\alpha>8$ then the sense of the cross-phase peak is reversed (Kale et al. 2007). This may occur where magnetometer stations straddle the plasmapause, shown by " $A$ " and " $B$ " in Figure 1. If $\alpha=8$ then the crossphase signature disappears. This may also happen if the stations straddle the boundary of the plasmapause, providing an averaged, misleading sense of the variation in resonant frequency, as represented by points " $A$ " and " $C$ " joined by the horizontal dashed lines in Figure 1. In any case, the disappearance of the cross-phase peak is a characteristic signature of the plasmapause and can be used to track its motion over a ground array (Milling et al. 2001).

Mass densities presented in this paper were estimated from the observed FLR frequencies following the procedure outlined in Menk et al. (1999, 2004). Magnetometer data were obtained from the IMAGE, SAMNET and MEASURE arrays, and two stations on the Antarctic peninsula. IMAGE (International Monitor for Auroral Geomagnetic Effects) is a 31-station digital array spanning Scandinavia and northern Europe, while SAMNET (Sub Auroral Magnetometer Network) stations span the UK and Scandinavia. MEASURE is a meridional array of paired magnetometers along the east coast of the United States. All these arrays contribute to the SuperMAG ground magnetometer network and database (Gjerloev 2012).

In determining the mass density we have assumed a fieldaligned density distribution of the form $R^{-3}$ and used a simple dipole magnetic field model. The first assumption introduces an error in density typically less than that arising from experimental error in determining the resonant frequency (about $25 \%$ ), while the second assumption leads to an overestimate of mass density that increases with increasing $L$ value and magnetic activity (Berube et al. 2006), being around 30\% at $L=3.0$ when $D s t=-50 \mathrm{nT}$. In addition the asymmetry of the geomagnetic field leads to a longitudinal variation that enhances mass and electron densities in December months at American longitudes (Menk et al. 2012).

\subsection{In situ electron densities and plasmaspheric imaging}

In this study we compare mass densities derived from ground magnetometer measurements of resonance frequencies with in situ measurements of electron densities from the Radio Plasma Imager (RPI) experiment (Reinisch et al. 2001) on board the IMAGE spacecraft (Burch 2003). IMAGE operated in an elliptical polar orbit with apogee at $7.2 \mathrm{R}_{\mathrm{E}}$ $(46,000 \mathrm{~km})$, perigee at $1,000 \mathrm{~km}$ altitude and $14.2 \mathrm{~h}$ orbital period. The RPI instrument is a low-power radar that alternates between active and passive mode and spans the plasma resonance frequencies characteristic of the magnetosphere. We used data obtained from the RPI database at Dartmouth University for the passive mode in which the RPI received natural plasma wave emissions from $3 \mathrm{kHz}$ to $1.1 \mathrm{MHz}$ and the electron number density is determined (to within a few percent) from the upper hybrid emission band (Benson et al. 2004), or from the lower edge of a range of continuum radiation (e.g. Goldstein et al. 2003). The densities were derived with an automatic fitting algorithm and manual correction.

For the studies described here we only examined RPI measurements from 07 to 16 MLT that were also within $\pm 30^{\circ}$ of the magnetic equator. Following Vellante \& Föster (2006) we assumed that electron density is constant along field lines over this latitude range. This assumption is true for diffusive equilibrium conditions and in reasonable agreement with results from a detailed study of RPI data by Ozhogin et al. (2012), although there can be considerable variation between individual measurements, and somewhat steeper density gradients more than about $\pm 20^{\circ}$ off the magnetic equator.

We have also used images from the EUV experiment on the IMAGE spacecraft, which provides line of sight measurements of sunlight resonantly scattered at $30.4 \mathrm{~nm}$ from $\mathrm{He}^{+}$ions, thus imaging the plasmasphere and related structures. These images were mapped to the magnetic equatorial plane as described by Sandel et al. (2003).

\subsection{Total electron content measurements}

Information on plasmaspheric electron density can also be obtained from GPS observations. Measurements of integrated columnar total electron content (TEC) from dual frequency GPS receivers either on the ground or in low Earth orbit (LEO) can be used in tomographic inversion of multiple slant TEC observations across a region (Yizengaw \& Moldwin 2005). The technique has been used, in conjunction with EUV imaging, to correlate the location of the mid-latitude ionospheric trough with the low altitude extension of the plasmapause (Yizengaw \& Moldwin 2005), to image upward fieldaligned flows from the ionosphere (Yizengaw et al. 2006a) and to map plasmaspheric plumes to the ionosphere (Foster et al. 2002; Yizengaw et al. 2006b). Here we use electron density profiles obtained from tomographic construction of data from the GPS receiver on the Australian FedSat spacecraft, in a sun-synchronous $800 \mathrm{~km}$ altitude orbit in the $1,030 \mathrm{LT}$ frame (Fraser 2003). The data were averaged over $\pm 30^{\circ}$ latitude to obtain equatorial electron density profiles.

\section{Results}

\subsection{Storm-time plasmaspheric density}

In order to illustrate the use of magnetometer arrays to monitor mass density within the plasmasphere we consider the interval 9-23 December 2003, which follows a $K p=6^{-}$, $D s t=-55 \mathrm{nT}$ disturbance over 5-8 December. $K p$ reached $5^{+}$on 10 December and $6^{-}$early on 11 December, but stayed 
F. Menk et al.: Plasmapause remote sensing using magnetometer arrays
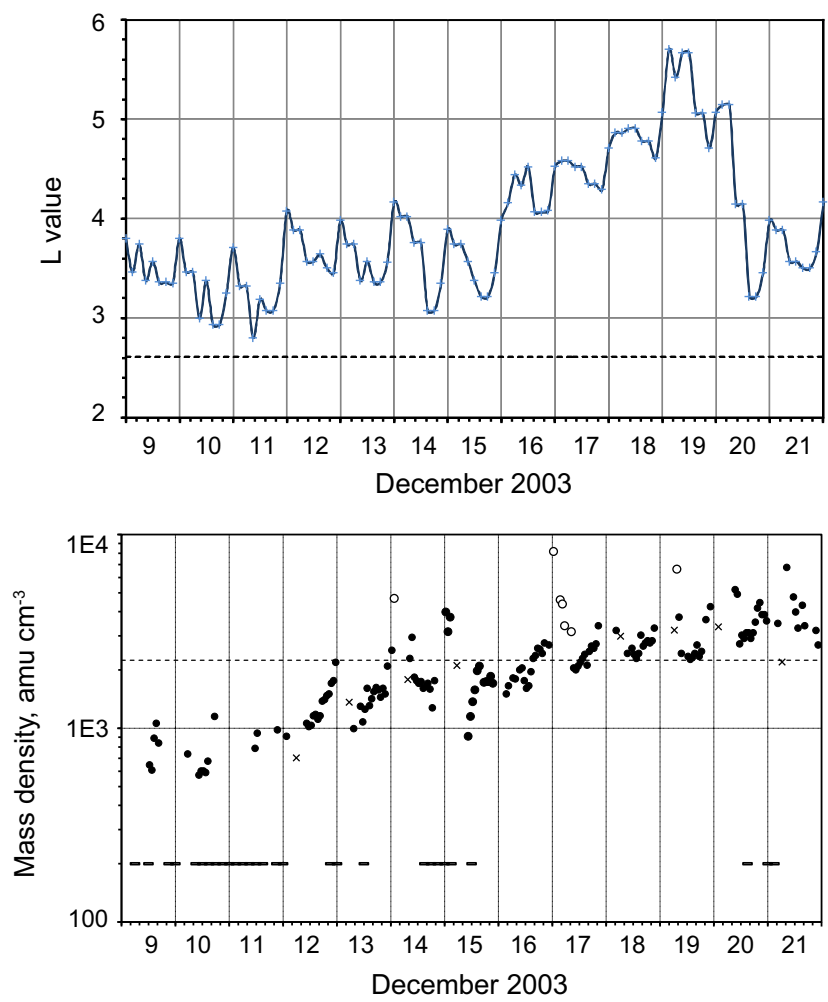

Fig. 2. (a) Plasmapause location given by Moldwin et al. (2002) model for 9-21 December 2003. Horizontal dashed line at $L=2.61$ shows location of magnetometer pair midpoint. (b) Mass density at $L=2.61$ over 9-21 December 2003. Solid horizontal lines indicate intervals where $K p \geq 4^{+}$; dashed horizontal line represents average mass density from the Berube et al. (2005) model. Open circles identify likely quarter mode oscillations and crosses denote VLFderived electron densities.

above 4 until 15 December, reaching $K p=5^{-}$again on 20 December. Dst reached a minimum of $-51 \mathrm{nT}$ at $20 \mathrm{UT}$ on 10 December.

The expected plasmapause $L$ value given by Eq. (2) for the period of interest is shown in Figure 2a. Mass densities were estimated using FLR cross-phase measurements between two magnetometer stations centred at $L=2.61$ on the Antarctic peninsula, Vernadsky and the low power magnetometer M3. Further details on these appear in Clilverd et al. (2003). The horizontal dashed line in Figure 2a identifies the midpoint $L$ value of the ground stations, which was at all times inside the expected plasmapause.

The variation in mass density at $L=2.61$ over this interval is presented in Figure $2 b$, where LT $\approx$ UT- 4 . The ordinate axis represents mass density in units of amu cm${ }^{-3}$, which is the same as the number density if the plasma contains no heavy ions. Periods where $K p \geq 4^{+}$are identified by solid horizontal lines. The horizontal dashed line at $2245 \mathrm{amu} \mathrm{cm}{ }^{-3}$ indicates the average expected mass density from Eq. (4). Densities are below this value during the moderately disturbed period over 9-13 December and increase over subsequent days due to refilling from the underlying ionosphere. This is discussed further in Section 3.2. Refilling also results in the diurnal variation in density evident on 12, 13 December and after 16 December.

Unusually high density values appear in the early local morning and late evening on some days. These may be due to heavy ion mass loading, for example associated with an oxygen torus (Fraser et al. 2005; Grew et al. 2007), or quarter and intermediate wave mode field line oscillations when there is a strong asymmetry in ionospheric conductances at conjugate ends of the field line. The quarter wave modes are identified by open circles and occur most often in December and June months at east American longitudes, resulting in greatly overestimated mass density (Obana et al. 2008).

Crosses in Figure $2 \mathrm{~b}$ denote electron densities obtained from Doppler measurements of ducted whister-mode signals from high power VLF transmitters. The VLF receiver was located at Rothera $(L=2.7)$ and densities were scaled to $L=2.61$ assuming an $R^{-3}$ power law. The electron densities are from around 02 MLT but follow similar trends to the mass density values.

Comparing Figures $2 \mathrm{a}$ and $2 \mathrm{~b}$ clearly shows that mass densities inside the plasmasphere can decrease significantly during moderately disturbed conditions. However, the pronounced increases in density accompanying disturbed conditions on 14/15, 20 and 21 December indicate the presence of unusually high mass densities relative to the whistler-derived electron densities.

The cross-phase spectra show unusual features on a number of days. This is illustrated in Figure 3, which presents whole-day cross-phase spectra for 11, 15, 17 and 20 December. Features of interest are: (i) almost no cross-phase signature over all of 11 December; (ii) three cross-phase bands, with the upper and lower frequency bands exhibiting a reversed polarity (negative cross-phase), from 11-16 UT on 15 December; (iii) unusually low cross-phase frequency before 06 UT on 17 December; (iv) a well defined, relatively low and constant frequency cross-phase signature during enhanced magnetic activity on 20 December. Point (i) suggests movement of the plasmapause over or near the station field lines, although this is not borne out by the model prediction of plasmapause position. Feature (ii) is associated with strong density gradients, discussed in Section 3.3. Feature (iii) is due to quarter mode field line oscillations, as mentioned above and (iv) relates to the high mass densities also mentioned above.

Further information on plasmasphere dynamics on 15 and 16 December comes from tomographic inversion of TEC data from the GPS receiver on the FedSat spacecraft, which on 16 December passed over the Antarctic Peninsula stations around 1400 UT and over New Zealand around 2230 UT. Geomagnetic activity was weakly disturbed with $K p<3$ throughout the day, although the equatorward boundary of the auroral oval extended to $-62^{\circ}$ MLAT at 0 MLT and $-64.6^{\circ}$ at 12 MLT at 17 UT.

The reconstructed electron density profile for the second pass was presented and discussed in detail by Yizengaw et al. (2006a) and clearly shows field-aligned low energy ion outflow from near the cusp region. Here we focus on the electron density profile for the equatorial plane for the 14 UT pass over the ground magnetometer stations. This is presented in Figure 4 and shows an irregular plasmapause with the inner boundary near $L=3.6-3.8$, somewhat lower than the $L$ values predicted by the Moldwin et al. (2002) and O'Brien \& Moldwin (2003) statistical models $(L=4.1$ and $L=3.9$ respectively). The TEC- and VLF-derived electron densities at $L=2.61$ are similar to the estimated mass densities.

\subsection{Storm-time evolution of the plasmapause and refilling}

We now consider how magnetometers can be used to investigate storm-time evolution of the plasmapause and subsequent 

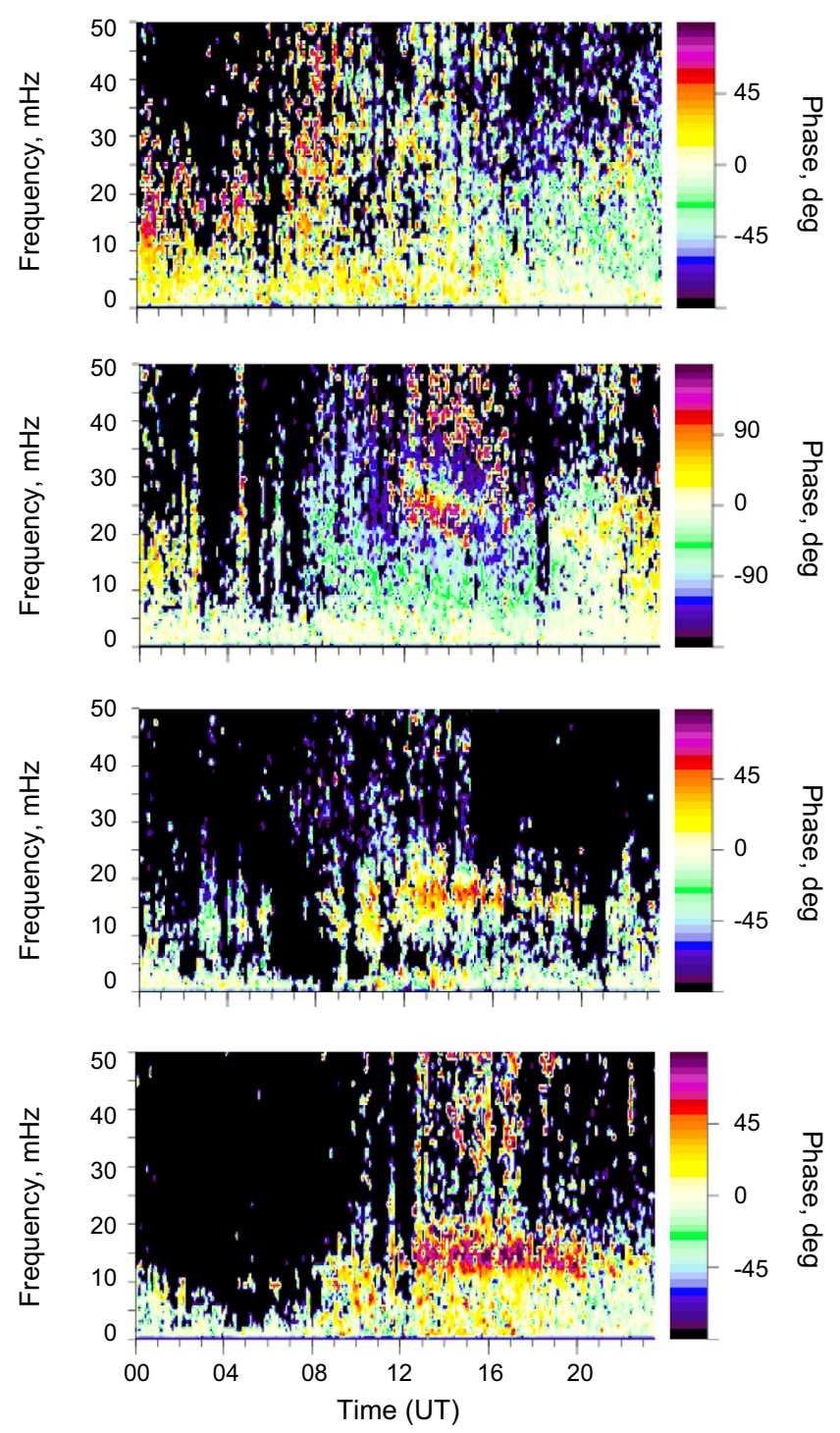

Fig. 3. Whole-day cross-phase spectra for $L=2.61$ Antarctic Peninsula stations for (top to bottom) 11, 15, 17 and 20 December 2003, respectively. Colour scale represents cross-phase magnitude and sign between the stations; note the different scale for 15 December. Horizontal cross-phase bands identify the resonant frequency.

refilling. We consider the illustrative interval 7-19 March 1998. General geophysical conditions are summarized in the top panel of Figure 5. Magnetic activity was low for several days prior to a storm that commenced on 9 March. Peak activity values were $K p=7^{+}$at $18-21 \mathrm{UT}$ and $D s t=-116 \mathrm{nT}$ at $20 \mathrm{UT}$, both on 10 March. Both indices recovered to lower values over the next few days, with a short increase in disturbance levels early on 15 March.

Magnetometer data were examined for all stations of the SAMNET and IMAGE ground arrays. Data were sampled at (or resampled to) $10 \mathrm{~s}$ cadence, and cross-power, power ratio and cross-phase spectra were examined for 27 combinations of nearby station pairs with midpoints ranging from $L=2.8$ to $L=9.9$. The resultant mass density profiles for $12 \mathrm{UT}$ $(\approx 13$ LT $)$ on each day are shown in the bottom panel of Figure 5. Each profile is plotted such that the point immediately above the date label is at $L=6$, and each adjacent date label represents a step of $L=1$. Even days are plotted with

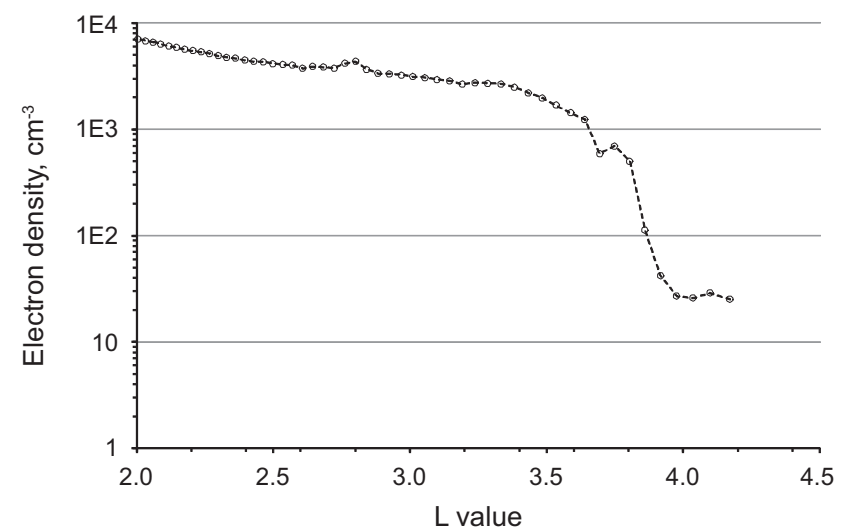

Fig. 4. GPS TEC-derived electron density profile for 1400 UT, 16 December 2003.

heavy lines. An asterisk on or near each plot identifies the latitude (not density) of the 12 MLT plasmapause determined using Eq. (3).

The results show that before the storm the plasmasphere was nearly saturated with an almost constant mass density gradient across the expected plasmapause position. This is particularly evident on 7 March. For comparison, the superimposed dotted and dashed lines for this day represent the saturated plasmasphere electron and mass densities predicted by the models described by Berube et al. (2005).

The storm main phase on 11 March produced a marked reduction in mass density compared with the previous day, especially at lower $L$ values. This is illustrated in the top panel of Figure 6, which shows the 12 UT mass densities at selected $L$ values over 9-17 March inclusive. Open circles represent the plasmapause location given by Eq. (3). These correspond well with the observed densities except on 11 March when the plasmapause was likely eroded to just equatorward of $L=2.82$. Plasmaspheric erosion followed by refilling is evident when comparing the change in density with plasmapause position at $L=2.82,3.57$ and 4.02 on subsequent days.

A more precise picture of flux tube refilling is obtained by examining the rate of density change with higher time resolution. This is illustrated in the bottom panel of Figure 6, which shows mass density determined each 20 min from FLR measurements at two station pairs over $03-17$ UT $(\approx 04-18$ LT) on 12 March. Both station pair midpoints map to outside the plasmapause over these times. The error bar at 5 UT represents typical uncertainty related to measurement of the resonant frequency. Mass density increased more or less steadily at both stations at around 4-5 amu $\mathrm{cm}^{-3}$, being higher for the low latitude station, although there are small local variations. This refilling rate equates to an upward ion flux at $1000 \mathrm{~km}$ altitude of around $0.8 \times 10^{8} \mathrm{amu} \mathrm{cm} \mathrm{cm}^{-2} \mathrm{~s}^{-1}$.

Detailed inspection of the 11 March density profile in the bottom panel in Figure 5 suggests latitude-dependent density structures may be present. To more clearly represent this we have plotted in Figure 7 the variation in FLR-derived mass density for the outer magnetosphere, where the time axis arises from rotation of the magnetometer array stations with Earth. Magnetospheric structures that change with UT or do not corotate would result in a temporal feature in the plot. The plot shows that density is enhanced (relative to lower $L$ values) for several hours over $L=4.3-5.6$, with additional density enhancements extending to higher $L$ just before 05 UT, 

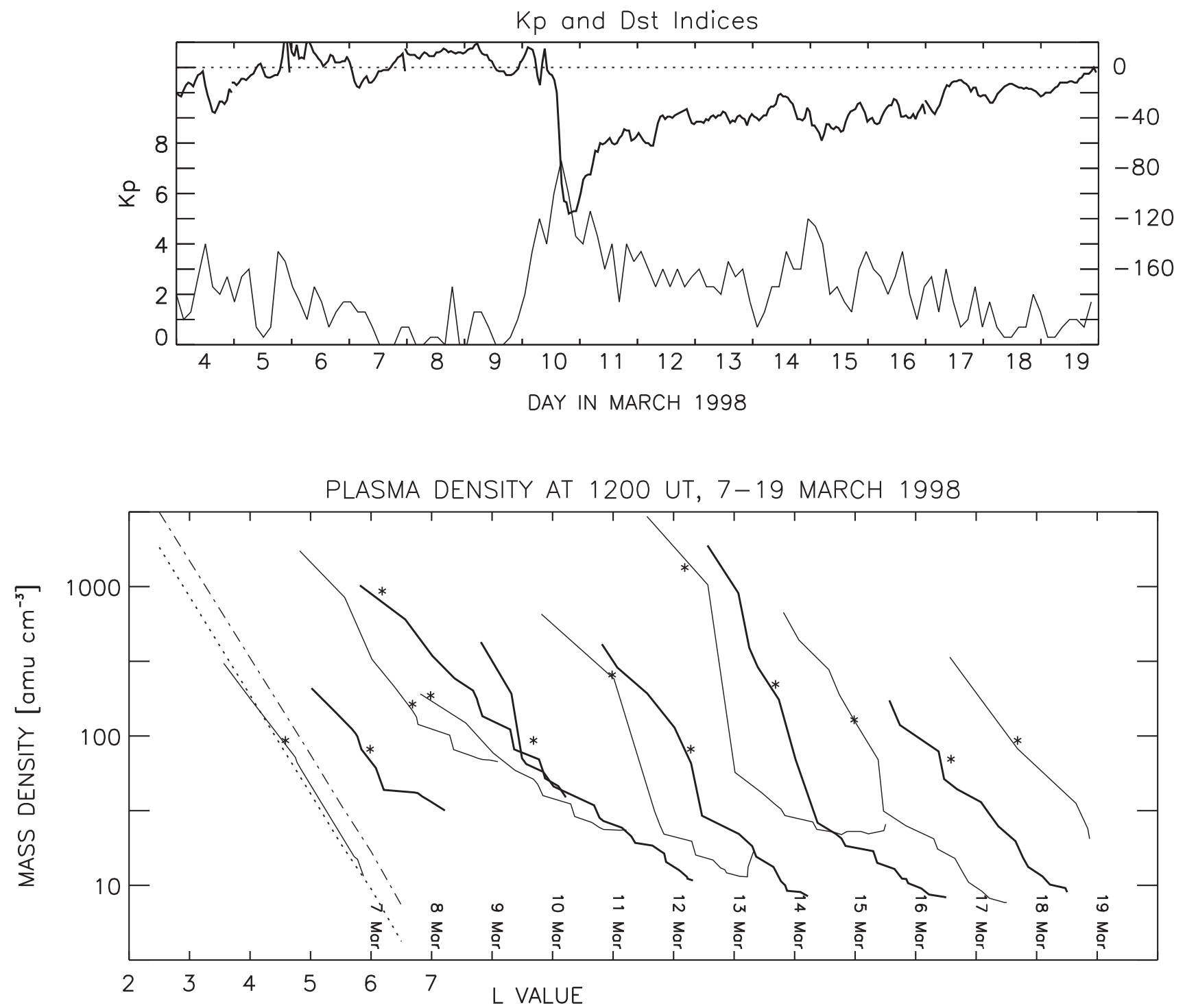

Fig. 5. Top: Kp and Dst over 4-19 March 1998. Bottom: mass density profiles at 1200 UT (LT $\approx$ UT +1$)$ over 7-19 March 1998. For each profile $L=6$ is above the corresponding date label, and an asterisk identifies the plasmapause latitude given by the Moldwin et al. (2002) model. Heavy lines represent even-numbered days. Diagonal dotted and dashed lines at 7 March denote saturated plasmasphere electron and mass densities from the Berube et al. (2005) models.

between 07 and 09 UT and after 13 UT. This suggests a complex pattern of convection and plasma erosion during the storm main phase. A region of high density beyond the main plasmasphere $(L>6.5)$ from 03 to 07 UT may be due to a significant heavy ion population or a dense plume feature.

\subsection{Detection of drainage plumes}

Figure 1 shows that a plume-like density enhancement may produce a distinct change in resonant frequency, although the form of this profile will be affected by field line distortion and the presence of heavy ions. Grew et al. (2007) reported the detection of a drainage plume and plasmaspheric biteout using ground magnetometer FLR measurements. Here we outline a different method for the detection of such density structures.

We suppose that steep density gradients associated with a sharp plasmapause, plumes and other features such as biteouts, may be manifested in ground data as cross-phase reversals. To investigate this we searched for steep density gradients at or near the plasmapause over the year 2001 using in situ electron density data from the RPI instrument on the IMAGE satellite. Considering only data from within $30^{\circ}$ of the magnetic equator, to identify steep gradients we used the criteria $\alpha>8$, $2.5<L<5.50,4000<n_{\mathrm{e}}<10$ and $\Delta n_{\mathrm{e}}>100$, where $n_{\mathrm{e}}$ is electron density. We also required the satellite footprint to be within $5^{\circ}$ geographic longitude of ground magnetometer stations.

Sixteen steep plasmapause events were identified in this way, 14 of these in the European region. For all these events we then examined dynamic cross-phase spectra from stations of the SAMNET and IMAGE magnetometer arrays straddling the expected plasmapause location. IMAGE EUV images were also inspected, where available, in order to study the global structure of the plasmasphere for these events.

Reversed cross-phase peaks were found to be characteristic of such RPI-identified steep plasmapause crossings. In addition, double maxima, i.e. two bands of enhanced cross-phase but with different sense of phase polarity for one band, were also often observed, and occasionally three bands were seen, 


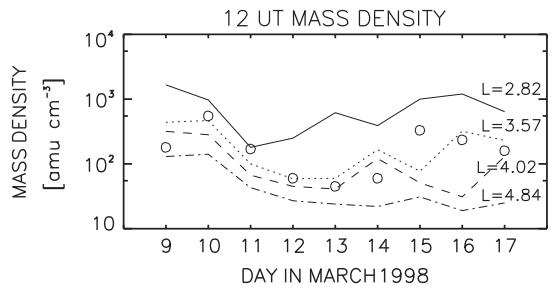

PLASMA DENSITY 12 MARCH 1998

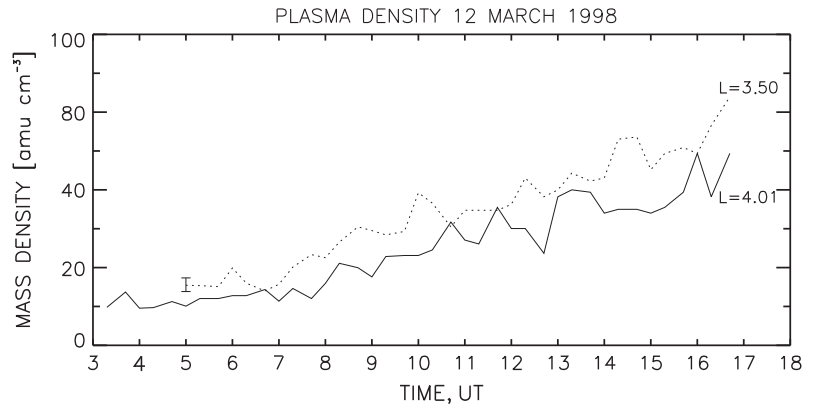

Fig. 6. Top: 12 UT mass densities at selected $L$ values over 9-17 March. Open circles represent plasmapause location given by Moldwin et al. (2002) model. Bottom: detailed view of mass density refilling for two nearby station pairs on 12 March.

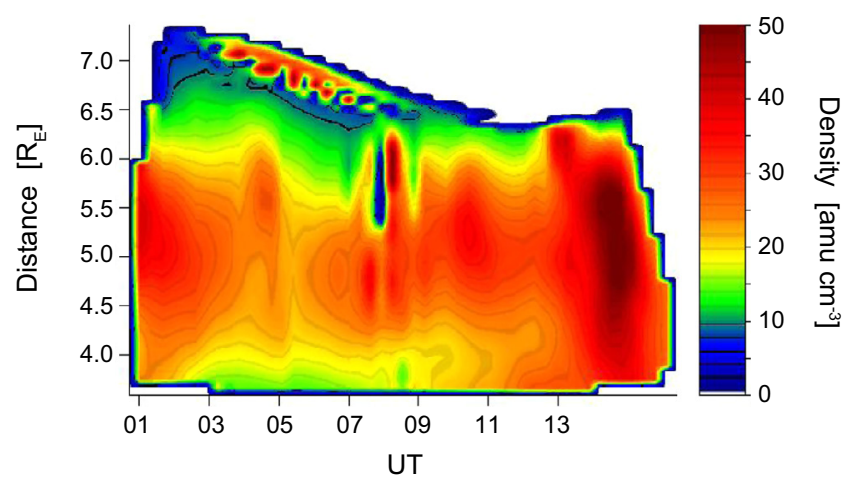

Fig. 7. Contour map showing spatio-temporal variation in mass density on 11 March 1998 using FLR measurements from stations in the IMAGE ground magnetometer array.

where the mid-frequency band is of opposite cross-phase sign. An example of such an event on 15 December 2003 was shown in Figure 3. The EUV images for 2001 showed the formation of a plume for 3 of the 16 events, and a clearly defined, sharp plasmapause for 12 events. The remaining event did not have adequate EUV images to offer a global view.

Of the 16 events observed, 6 were during a storm main phase and the remaining 10 during quiet intervals, some of these post-storm.

For 6 of the RPI steep plasmapause events we were able to determine the equatorial Alfvén speed and hence FLR profiles based on piecewise linear fits to the RPI electron density profiles. These profiles showed complex density features at the times of interest. Example electron density profiles and the derived resonant frequency profiles are shown for 11 June and 27 June in Figures $8 \mathrm{a}$ and $8 \mathrm{~b}$ respectively. In both cases the top panel is for the first IMAGE pass over the ground magnetometer array and the second panel is for the next pass at the same local time. For example, on 11 June (Fig. 8a) the RPI-derived electron density measurements for the first pass, represented by stars, show density decreasing with increasing
$L$ value except for a strange enhancement near $L=3.8$. The overplotted curve shows a model fit to this profile assuming a power law with radial distance $R^{-\alpha}$ where $\alpha=2.5$ for $L<2.5, \quad \alpha=4.5$ for $2.5<L<3.5, \quad \alpha=-1.5$ for $3.5<L<3.8, \alpha=9.0$ for $3.8<L<4.0$ and $\alpha=1.5$ for $L>4.0$.

At the second pass about $15 \mathrm{~h}$ later in UT but at a similar local time, the inner boundary of the plasmapause has moved to $L=3.65$ and the inner region has filled, but the enhanced density feature now appears at $L=4.4$. The model fit here was achieved using a similar process but with slightly different fitting parameters.

The bottom panel in Figure 8a shows the expected FLR profile for these two passes, assuming a purely electron-proton plasma and a dipole geomagnetic field. Despite these limitations the plot suggests distinct changes in resonant frequency should be experimentally observable.

Figure $8 \mathrm{~b}$ shows similar temporal evolution of a density enhancement outside the plasmasphere on 27 June 2001. Another event we similarly examined, on 24 November 2001, exhibited a density depletion (biteout) between $L=3.0$ and $L=3.7$. This is not shown here but is similar to the model biteout represented in Figure 1 and reported by Grew et al. (2007).

We now focus in more detail on results for 11 June 2001. This was in the recovery phase of a $K p=6^{-}$magnetic storm which commenced on 9 June. Geomagnetic and solar wind conditions for this storm were described by Spasojević et al. (2003). According to the Moldwin et al. (2002) model the plasmapause eroded to around $L=2.8$ early on 10 June but by the time of the two orbits shown in Figure $8 \mathrm{a}$ had recovered to $L=4.33$ and $L=4.62$, respectively. These are somewhat higher $L$ values than the plasmapause positions shown in Figure 8a.

Mass densities determined using ground magnetometers in the SAMNET $(\mathrm{LT} \approx \mathrm{UT})$, IMAGE $(\mathrm{LT} \approx \mathrm{UT}+1)$ and MEASURE (LT $\approx$ UT -5 ) arrays are plotted in Figure 9. At $L=2.4$ mass densities were slightly higher on 11 June and early 12 June than on the earlier days. Densities at $L=2.6$, $\mathrm{LT}=\mathrm{UT}$ (solid triangles) followed the same trend but were significantly lower at LT $=\mathrm{UT}-5$ (open triangles). However, densities at $L=3.6$ (plus symbols) and $L=3.9 / 4.0$ (diamonds) were greatly reduced and different across only one hour in LT on 11 June, indicating equatorward erosion of a spatiallyvarying plasmapause.

Whole day dynamic cross-phase spectra for 11 June were presented by Menk \& Waters (2013) for ground magnetometer station pairs centred on $L=3.2$ and $L=3.9$ and are not repeated here. At $L=3.9$ they show two cross-phase bands (negative near $15 \mathrm{mHz}$ and positive from 17 to $25 \mathrm{mHz}$ ) before 0930 UT, after which the upper positive band also switches to negative. At $L=3.2$ there are three cross-phase bands, with reversed cross-phase at the middle frequency. The frequencies of the three bands decrease with time, at 08 UT being around 15, 18-20 and 23-30 mHz. Based on the detailed analysis of this event in Spasojević et al. (2003), the density structures shown in Figure $8 \mathrm{a}$ are likely associated with remnants of a wrapped drainage plume and a low density cold plasma channel between this and the main plasmasphere.

The expected FLR frequencies, amplitudes and phases at the ground were determined by incorporating the inferred Alfvén speed profiles into a two-dimensional numerical MHD model of the coupled magnetosphere-ionosphere 
F. Menk et al.: Plasmapause remote sensing using magnetometer arrays
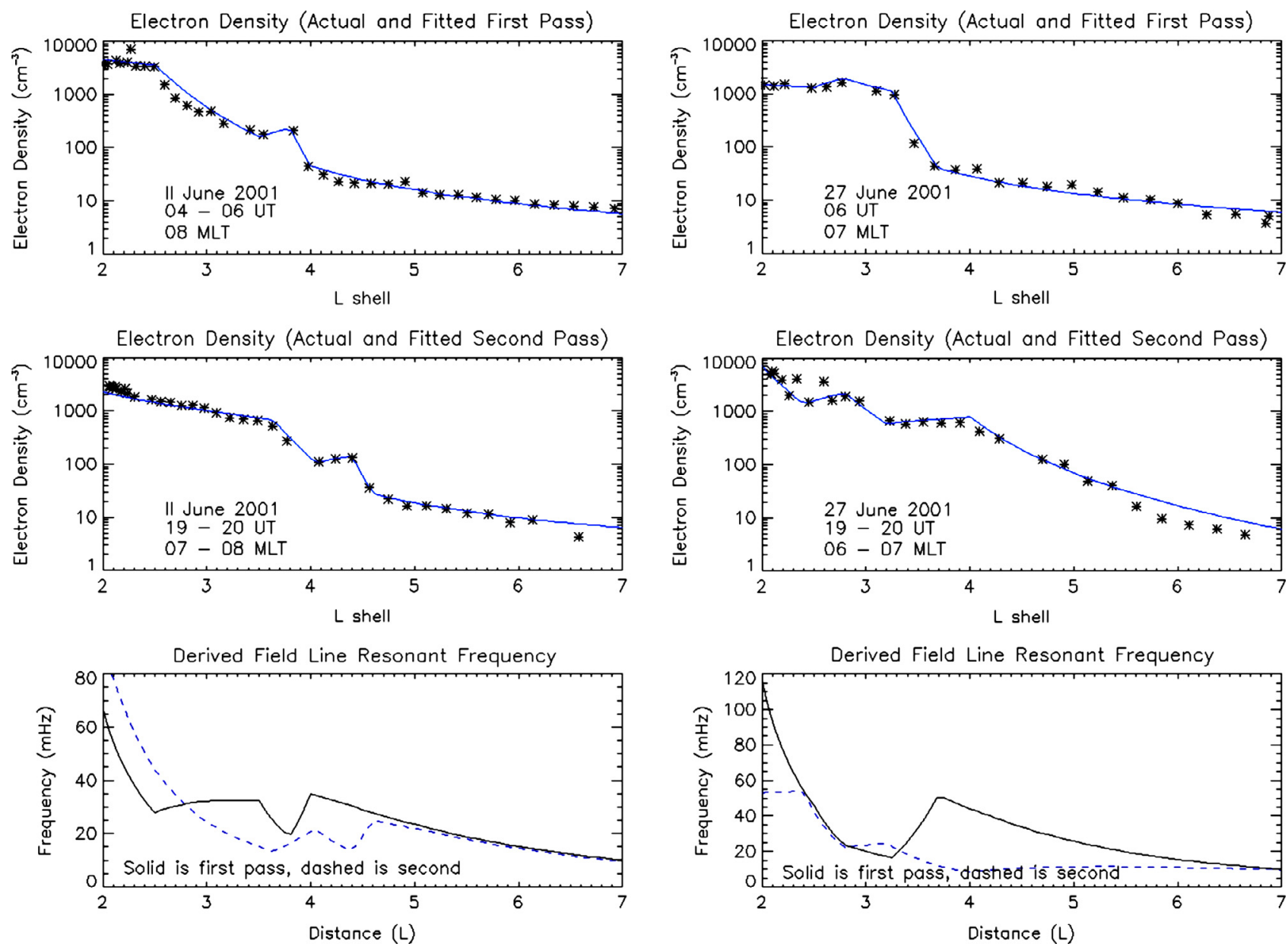

Fig. 8. (a) Top and middle: in situ electron density measurements (stars) and piecewise linear fits for two IMAGE satellite passes on 11 June 2001. Bottom: resultant inferred FLR profile for these two passes based on Alfvén speed derived from electron density measurements. (b) Same as Figure 8a except for 27 June 2001.

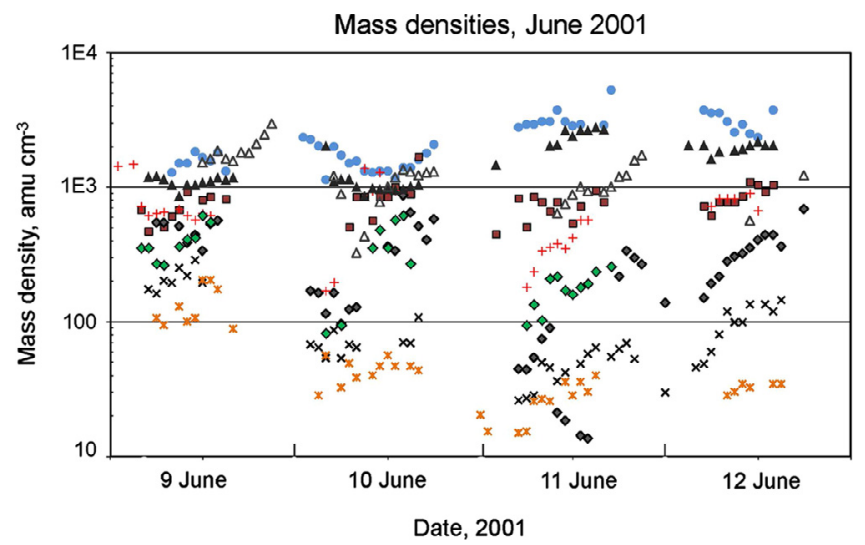

Fig. 9. FLR-derived mass densities for 9-12 June 2001. Symbols are as follows: $L=2.4, \quad \mathrm{LT}=\mathrm{UT}=$ blue circles; $L=2.6$, $\mathrm{LT}=\mathrm{UT}=$ black triangles and $\mathrm{LT}=\mathrm{UT}-5=$ open triangles; $L=3.2, \mathrm{LT}=\mathrm{UT}=$ brown squares; $L=3.6, \mathrm{LT}=\mathrm{UT}+1=$ plus symbols; $\quad L=3.9 / 4.0, \quad \mathrm{LT}=\mathrm{UT}=$ grey $\quad$ diamonds $\quad$ and $\mathrm{LT}=\mathrm{UT}+1=$ green diamonds; $L=4.7, \mathrm{LT}=\mathrm{UT}+1=$ crosses; $L=5.7, \mathrm{LT}=\mathrm{UT}+1=$ orange stars.

(Waters \& Sciffer 2008). The outer boundary of the model is set at $10 R_{E}$ and the inner boundary is formed by the ionosphere described by the International reference ionosphere (IRI) and Mass spectrometer and incoherent scatter radar
(MSIS) models for the day being considered. The model was driven by a fast mode pulse at the outer boundary with a Gaussian spatial distribution and uniform spectral content across the $1-100 \mathrm{mHz}$ frequency range. The azimuthal wave number, $m$, was set to 2 , and the ionospheric Pedersen and Hall conductances were both set to $5 \mathrm{~S}$.

The Alfvén speed and plasma density profiles for the noon meridian plane are presented in Figure 10. The inferred plasmapause structure is evident. The resultant ground level north-south component power spectral density and cross-phase between stations separated by 2 degrees in latitude are shown in Figure 11. Alternate dashed and dotted lines in the top panel denote odd and even harmonics respectively, with frequency indicated on the ordinate axis. The abscissa extends to the outer boundary at $10 \mathrm{R}_{\mathrm{E}}$. Power enhancements represent regions where incoming compressional mode waves couple to local resonances at harmonics of the toroidal mode eigenfrequencies. The three alternating cross-phase bands seen in the actual data at $L=3.2$ are reproduced by the model, highlighted by the vertical dashed line. These features are associated with the sudden decrease in resonant frequency (increase in density) at the inner edge of the density enhancement. The two crossphase bands seen in actual ground magnetometer data near $L=3.9$ are also reproduced by the model and are associated with the steeply increasing resonant frequency (decreasing density) on the outer edge of the density feature. 

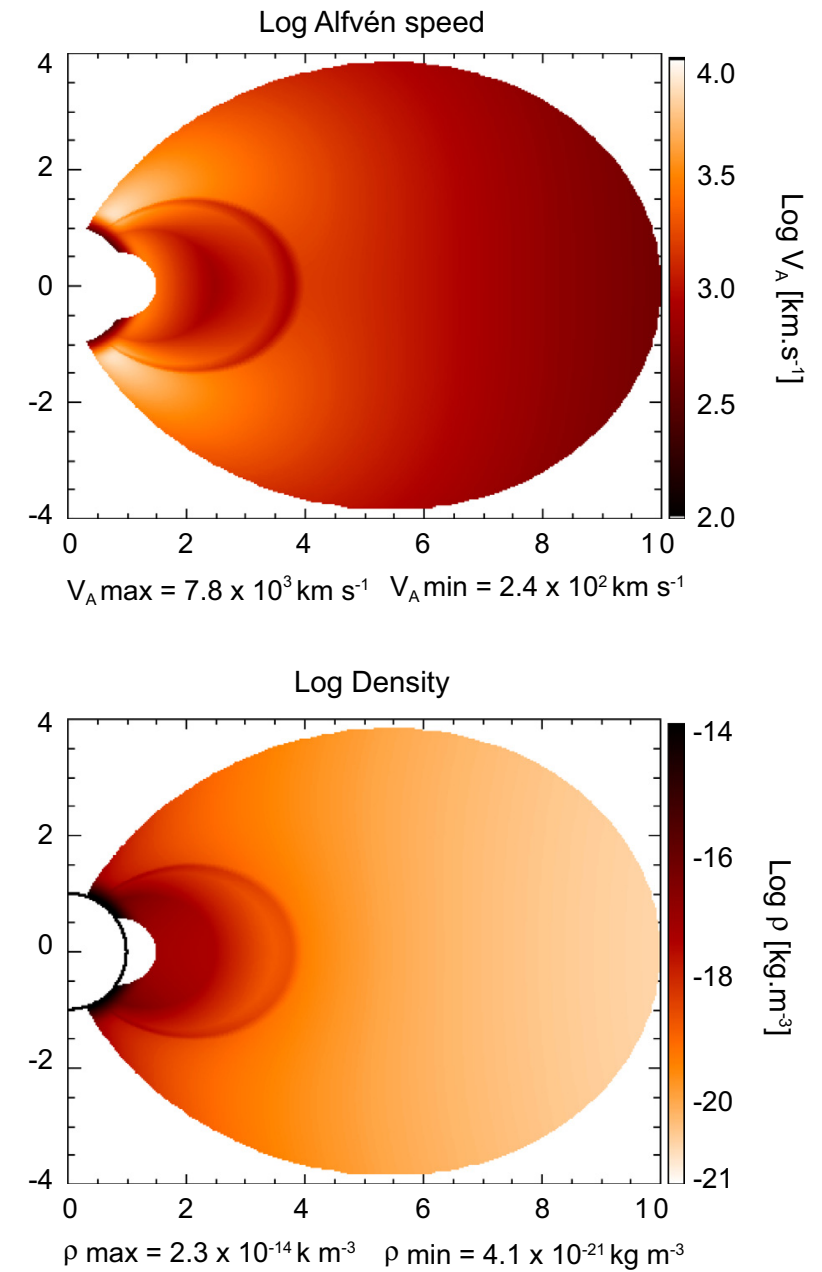

Fig. 10. Alfvén speed (top) and plasma density (bottom) profiles for the noon meridian plane (Sun to the right) used in the 2D MHD simulation for 11 June 2001. $X$ - and $y$-axes are in units of $\mathrm{R}_{\mathrm{E}}$. The inner boundary is a realistic ionosphere and the outer boundary is at $10 \mathrm{R}_{\mathrm{E}}$.

\section{Discussion}

\subsection{Storm-time density within the plasmasphere}

\subsubsection{Summary of observations}

The observations presented in Section 3.1 showed that: (i) ground-based magnetometers can be used to routinely monitor plasmaspheric mass density, showing features such as storm-time depletion and refilling; (ii) mass density deep within the plasmasphere can be significantly reduced during moderately disturbed $(K p=4-5)$ periods; (iii) movement of the plasmapause to near or over the ground stations may be accompanied by loss or reversal of the cross-phase signature; (iv) during disturbed periods mass density near the plasmapause may be significantly higher than electron number density, indicating the presence of heavy ions.

\subsubsection{Density changes within the plasmasphere}

Figures 2 and 3 show that increases in $K p$ and movement of the plasmapause (given by empirical models) to within $0.3-0.7 R_{E}$ of the $L=2.61$ ground stations on 10,11, 14 and 15 December caused decreases in mass density of order $50 \%$ within a few hours. Kim et al. (2007) reported no such decrease in mass density at $L \leq 2.9$ during a $K p=8^{+}$storm although Chi et al. (2000) found that mass density at $L=2$ dropped to about one third of quiet values during a similar storm. In agreement with Chi et al., we also found substantial density recovery within a day.

\subsubsection{Is the model plasmapause location correct?}

It is possible that the Earthward boundary of the plasmapause moved to lower latitudes than predicated by the statistical models, to near or over the $L=2.61$ ground stations. Evidence for this is the loss of cross-phase signature in Figure 3 on 11 December, and, as explained later, reversal in the sense of that signature on 15 December. Further evidence comes from the TEC-derived electron density profile in Figure 4, for a satellite pass directly over the ground magnetometer stations on 16 December. This clearly shows the plasmapause to be somewhat irregular in shape and with the inner boundary near $L=3.6-3.8$, about 0.4 and $0.2 \mathrm{R}_{\mathrm{E}}$ inward of the Moldwin et al. (2002) and O'Brien \& Moldwin (2003) models, respectively. Such a discrepancy cannot account for the decrease in density on 10 and 15 December.

As mentioned in Section 2.1, if mass density decreases with radial distance as $\mathrm{R}^{-8}$ then the cross-phase signature disappears between magnetometer stations monitoring field lines mapping to this region, such as for those labelled " $\mathrm{A}$ " and " $\mathrm{B}$ " in Figure 1. This can be used to identify an overhead plasmapause (Milling et al. 2001). However, stations " $A$ " and " $C$ " straddling the plasmapause boundary provide a misleading indication of the change in resonant frequency. This can cause the cross-phase peak to diminish to the point where it is no longer detectable, but also averages the frequency variation so that the minimum frequency at the boundary is not detected and the inferred mass density is lower than reality. This may partly explain the inferred sudden reduction in mass density on 15 December seen in Figure $2 b$.

\subsubsection{Enhanced storm-time density}

The bottom panel in Figure 3 shows a sustained cross-phase signature around $12-15 \mathrm{mHz}$ on 20 December. As seen in Figure $2 b$, the FLR-derived mass densities on 20 and 21 December are $50-100 \%$ higher than expected for quiet times. These density enhancements accompany increased magnetic activity and are not what we would expect under enhanced convection and erosion of plasmaspheric plasma to the outer magnetosphere. It is likely that the mass density increases result from an increase in the proportion of heavy ions, especially $\mathrm{O}^{+}$, in the outer plasmasphere at this time. Comparison with the VLF-derived electron number density from the same location on 21 December suggests a mass loading factor of order 2.0-3.0. This would be achieved if the plasma comprised protons and $7-21 \% \mathrm{O}^{+}$by number. This is comfortably within the range reported by Berube et al. (2005).

\subsection{Storm-time plasmapause and refilling}

\subsubsection{Summary of observations}

Section 3.2 presented ground-based FLR observations during a canonical magnetic storm. This showed that (i) a ground magnetometer array can monitor evolution of the plasmapause density profile throughout a storm cycle; (ii) flux tube refilling can 


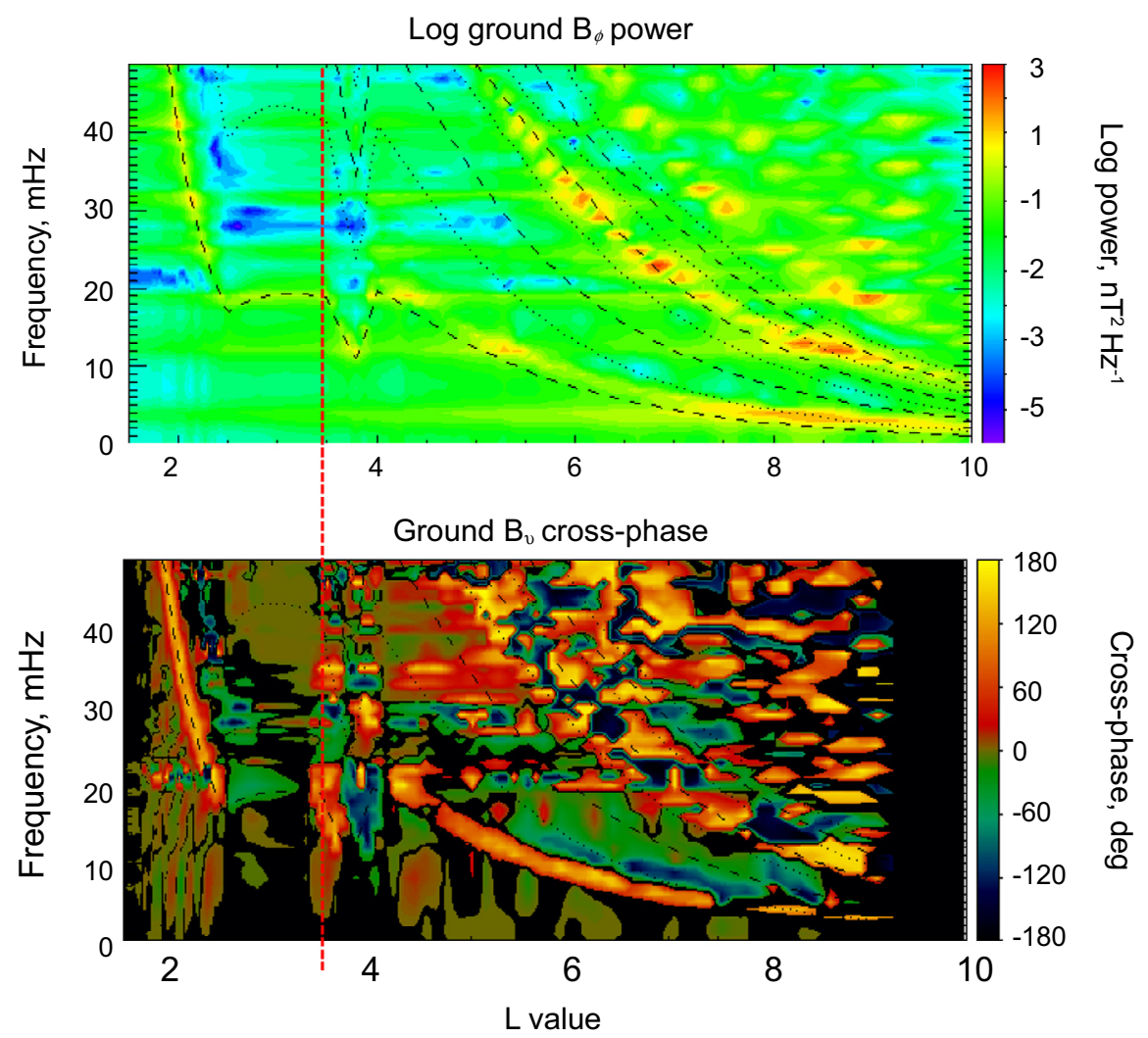

Fig. 11. Top: model ground level north-south component power spectral density. Alternate dashed and dotted lines denote odd and even harmonics, respectively. Bottom: model ground-level cross-phase between stations separated by 2 degrees in latitude. Vertical dotted line denotes region where three alternating cross-phase bands occur.

be measured; (iii) density irregularity structures can be detected near the plasmapause.

\subsubsection{Evolution of the plasmapause}

Figure 5 clearly shows changes in plasmapause shape over a typical magnetic storm. The pre-storm plasmasphere (e.g. 7 March) was saturated with no pronounced plasmapause. The observed mass densities were very close to model predictions including the Berube et al. (2005) electron density model and the Global Core Plasmasphere Model (Gallagher et al. 2000, not shown here). These comparisons suggest the ion population comprised mostly protons at this time.

The density profile on $10 \mathrm{March}$, at the beginning of the main phase, shows development of some irregularity structures but no distinct plasmapause profile. By 11 March, early in the recovery phase, mass density was greatly reduced compared with the previous day, especially at lower $L$ values. The stars in the bottom panel of Figure 5 show that the Moldwin et al. (2002) model plasmapause locations agree reasonably well but not exactly with the plasmapause position monitored by the FLR measurements. The measured profiles often exhibit irregular structure. This is also seen in the top panel of Figure 6a, where densities at middle latitudes varied irregularly during the disturbed period over 11-16 March. This results from a complex interplay of refilling, convective erosion, heavy ion mass loading and field line distortion.

Earlier it was mentioned that the plasmapause profile is smoothed and mass density underestimated if ground stations straddle the plasmapause boundary. This effect is compounded by spatial integration effects whereby a sharp change in the ionospheric Hall currents is smeared out at the ground (Poulter \& Allan 1986). The frequency variation across the plasmapause detected by ground magnetometers is therefore smoothed by a factor that depends on the density gradient in the equatorial plane. Poulter and Allan estimated that for a one $\mathrm{R}_{\mathrm{E}}$ wide plasmapause the resonant frequency is increased by $\sim 15 \%$ at the equatorward edge of the plasmapause and decreased by $\sim 25 \%$ at the poleward edge.

\subsubsection{Effects of field line model}

The FLR technique estimates mass density and is affected by changes in mass loading near the equatorial plane, and the choice of field-aligned density model. These were discussed in detail by Vellante \& Föster (2006) and should not affect changes on the scales shown here. The mass density estimates are also sensitive to the magnetic field model used. The dipole model used to estimate the densities in Figures 5 and 6 will be inaccurate when there are rapid and significant changes in magnetospheric configuration, as for this storm. The error increases with increasing magnetic activity (Berube et al. 2006). The densities shown are therefore only approximate. Kale et al. $(2007,2009)$ showed that stretching of mid-latitude field lines during large storms can alter the inferred shape of the plasmapause profile. At high latitudes field line stretching near local dawn and dusk affects resonant frequencies (e.g. Waters et al. 1995) and the polarization of guided wave modes (Kabin et al. 2007). 


\subsubsection{Refilling}

The top panel of Figure 6 shows the variation in mass density at selected $L$ values over 9-17 March inclusive. The increase in mass density at $L=2.82$ over $12-15$ March relates to an equivalent daily refilling rate of around $200 \mathrm{amu} \mathrm{cm}{ }^{-3}$, compared with $\sim 400 \mathrm{amu} \mathrm{cm} \mathrm{cm}^{-3} \mathrm{~d}^{-1}$ at $L=2.6$ reported by Obana et al. (2010). This is reasonable since ongoing magnetic activity would cause additional plasma erosion and loss, for example on 15 March. This net rate represents the daily average of supply and loss processes and should be distinguished from the refilling rate associated purely with the upward ion flux on the dayside.

The bottom panel of Figure 6 affords a more detailed picture of flux tube refilling. Mass density increased more or less steadily at both stations at $4-5 \mathrm{amu} \mathrm{cm}{ }^{-3}$, corresponding to an upward ion flux at $1000 \mathrm{~km}$ altitude of around $0.8 \times 10^{8} \mathrm{amu} \mathrm{cm} \mathrm{cm}^{-2} \mathrm{~s}^{-1}$. This is comparable to but smaller than the rate observed at this latitude by Obana et al. (2010). Upward fluxes at lower latitudes will be higher due to the smaller flux tube volume. The short variations in the rate of mass density increase show that the upward flux varies around a mean value on time scales of an hour or so.

Over this interval the plasmapause was located at lower $L$ than the ground stations. The refilling discussed here is therefore to depleted flux tubes mapping outside the plasmasphere. A similar result was reported by Obana et al. (2010) and supports the argument by Reinisch et al. (2004) that during refilling periods the plasmapause, as determined by particle density measurements, does not coincide with the topological boundary between convecting and corotating plasma flow.

\subsubsection{Monitoring magnetospheric density}

Results presented here and illustrated in Figure 7 show that a north-south array of ground magnetometers can provide information on the mass density profile through the plasmasphere and magnetosphere. The time evolution of density features is monitored with the rotation of Earth. Longitudinally distributed stations are required for spatial information on corotating density features.

Such maps can be routinely implemented using automated algorithms, and would provide a "quick look" reference on the magnetosphere structure and dynamics. Several suitable magnetometer arrays exist and historical data are available, as shown here. The density data can also provide important inputs to data assimilative models (e.g. Lichtenberger et al. 2013).

\subsection{Detection of drainage plumes and other structures}

\subsubsection{Summary}

Results presented in Section 3.3 show that (i) cross-phase reversals and other features identify the presence of steep density gradients at drainage plumes, biteouts and other structures; and (ii) numerical modelling using realistic ionospheric boundary conditions is able to simulate the frequency and phase profiles measured by ground stations under such conditions.

\subsubsection{Identification of a plasmaspheric plume on 11 June}

We found 16 intervals in 2001 when steep density gradients were identified at the plasmapause using in situ electron density data. EUV images showed a sharp plasmapause for 12 of these events and formation of a plume for another 3 events. Cross-phase reversals and multiple bands of opposite crossphase sign were found to be signatures of such events. We were able to use electron density data to infer the equatorial Alfvén speed for 6 of these events. The resultant profiles showed complex structures near the plasmapause. Using numerical modelling of wave propagation in a realistic magnetosphere we then simulated the expected power and cross-phase patterns for ground array stations.

Magnetometer array data presented in Figure 9 for the 9-12 June storm interval show several trends. At lower latitudes $(L=2.4,2.6)$ mass densities in the European sector were not greatly affected, but plasma erosion decreased density at the east American, $L=2.61$ stations on 10 and 11 June. Mass densities at $L=3.2$ overall did not change much during the storm. Densities at $L \geq 3.6$ decreased greatly from 10 June with gradual recovery and subsequent refilling, indicating movement of the plasmapause to lower latitudes. Mass densities from the MEASURE array (open triangles) exhibit significant increases in the evenings on 9 and 11 June. Similar local time, summer increases were noted by Chi et al. (2013) but the cause is not clear.

Looking more carefully at the morning of 11 June, there was an approximate doubling of mass density at $L=4.0$ over about $4 \mathrm{~h}$. This coincides with the location of a density enhancement in the electron density profile shown at the same time in the top panel Figure 8a.

The evolution of a drainage plume during this storm was discussed in detail by Spasojević et al. (2003). A plume formed on 9 June but exhibited $L$-dependent rotation rates, so that the plume wrapped around the main plasmasphere, and due to ongoing activity a second plume was observed in EUV images late on 10 June, when pronounced shoulders were also present in the local morning and post-noon sectors. Here we identify the increase in mass density seen in Figure 9 near $L=3.9$ / 4.0 early on 11 June with the drainage plume. Abe et al. (2006) described the possible detection of a plume in ground magnetometer data on 10 June, by comparing the $\mathrm{H}$ component power ratio between two stations separated in both latitude and longitude with the plume location identified in EUV images. They did not present cross-phase measurements which are usually regarded as more reliable than the power ratio methods they used. Grew et al. (2007) demonstrated the detection of a drainage plume during an extended moderately disturbed interval in October 2001, through the local increase in mass density identified using cross-phase measurements, VLF electron density data and EUV observations. The increases in mass density we observed are consistent with these results.

Important additional information comes from consideration of the cross-phase structure. Two opposite sign crossphase bands were recorded at $L=3.9$ and three such bands at $L=3.2$. These are reproduced by the simulation modelling shown in Figure 11, which in conjunction with Spasojevic et al. (2003) analysis allows us to associate these features with remnants of a wrapped drainage plume and a low density cold plasma channel between this and the main plasmasphere.

\subsubsection{Identification of a bulge and drainage plume on 27 June}

Spasojević et al. (2003) also described in detail evolution of the plasmapause boundary and a drainage plume on 26-27 June. Figure $8 \mathrm{~b}$ shows RPI-derived electron density profiles for this 
day, with an enhancement in density in the top panel around $L=3.0-3.3$. Ground magneteometer data showed this enhancement, and loss of cross-phase signal (i.e. overhead plasmapause) at $L=3.6-3.9$ from 06 to $09 \mathrm{LT}$, with two cross-phase bands, one of reversed sign (i.e. strong density gradient, plasmapause moving outward) over 09-12 LT. Following results presented by Spasojević et al. (2003) we identify these earlier features with the western edge of a radially outward bulge or shoulder, and the inner boundary of the plasmapause near $L=3.4$. The 19-20 UT, 06-07 MLT IMAGE orbit crossed the plasmapause near the westward, outer edge of the plume.

For this example the ground magnetometer FLR observations have thus identified the bulge, the plasmapause boundary and the irregular outer edge of a plume.

\subsubsection{Numerical modelling}

The use of a numerical model to simulate the ground magnetometer signatures using actual data as input is novel. The model was described by Waters \& Sciffer (2008) and uses nonorthogonal basis functions to allow incorporation of a realistic ionosphere boundary (with Hall current and oblique geomagnetic field) and dipole field geometry in the magnetosphere. The ionosphere is represented by a thin current sheet at $120 \mathrm{~km}$ altitude. Ionospheric Hall and Pedersen conductances are specified by the IRI and MSIS models and were set at $5 \mathrm{~S}$ for this simulation. The outer boundary at $10 \mathrm{R}_{\mathrm{E}}$ is driven by a time-dependent field-aligned perturbation which produces a broadband compressional component that propagates through the magnetosphere. ULF wave propagation and resonance properties are largely determined by the variation of Alfvén speed, established by reference to in situ electron density data assuming a purely electron-proton plasma. The azimuthal wavenumber was set to 2 , which is typical for low latitude FLRs (e.g. Saka \& Kim 1985). The FLRs are normal modes of the system and are used to develop power and phase profiles across the ground. The resonance width is determined by the ionospheric conductance and is smaller in the ionosphere than on the ground.

Although the modelling makes some simplifying assumptions it reproduces the observations and thus confirms that multiple frequency bands of opposite cross-phase identify steep density structures associated with plasma drainage plumes, bulges and biteouts. This is an important result extending the utility of ground-based magnetometer observations for monitoring the plasmapause region.

\subsubsection{Wave propagation across the plasmapause}

Inspection of the top panel in Figure 11 shows that the model predicts reduced wave power within the plasmasphere at higher frequencies (above $22 \mathrm{mHz}$ ) compared with the outer magnetosphere. This is due to reflection, absorption and tunnelling of wave energy at the plasmapause (Moore et al. 1987; Zhang et al. 1993). The latter authors used 3-D ray tracing to show that compressional Pc3 waves propagating through the magnetosphere encounter an ion-ion cutoff between the $\mathrm{He}^{+}$and $\mathrm{O}^{+}$ gyroresonances. This imposes a bandpass filter so that only lower frequency waves penetrate to the inner magnetosphere. The location and bandwidth of the filtering action are governed by the $\mathrm{O}^{+}$concentration. Since this often increases near the plasmapause during magnetically active conditions more compressional Pc3 wave energy could enter the plasmasphere then.
In any case, the difference or ratio in Pc3 power may be measurably different between ground stations that straddle the plasmapause. In situ observations also reveal clear reductions in Pc5 wave power within the dayside plasmasphere compared to the plasmatrough (Hartinger et al. 2010), although this may also be related to different FLR conditions in these regions.

\section{Conclusions}

This paper has discussed remote sensing of the plasmasphere and plasmapause using measurements from existing groundbased magnetometers. The main results are as follows.

(i) A ground magnetometer array can routinely monitor mass density within the dayside plasmasphere and evolution of the plasmapause density profile throughout a storm cycle. Data are most conveniently examined via time series plots, density-latitude profiles, or latitude-time contour maps.

(ii) During disturbed times mass density can decrease within a few hours by $50 \%$ or more $0.5 \mathrm{R}_{\mathrm{E}}$ or further inward of the plasmapause.

(iii) Loss of the cross-phase signature identifies movement of the plasmapause to near or over the ground stations.

(iv) Refilling of depleted flux tubes mapping to within and outside the plasmapause is readily measured. For the example presented the upward flux, measured with $20 \mathrm{~min}$ resolution at $L=3.5$ and $L=4.01$, was around $0.8 \times 10^{8} \mathrm{amu} \mathrm{cm} \mathrm{cm}^{-2} \mathrm{~s}^{-1}$ relative to $1000 \mathrm{~km}$ altitude.

(v) The plasmapause position determined by magnetometer measurements is generally within $0.5 \mathrm{R}_{\mathrm{E}}$ of the location predicted by empirical statistical models, but reveals rapidly changing and complex structures under disturbed conditions. The magnetometer measurements are affected by mass loading, field line distortion and to a lesser extent, the assumed fieldaligned density distribution.

(vi) During disturbed periods mass density near the plasmapause may be several times higher than electron number density, due to the presence of heavy ions. In the example discussed mass density increased by $50-100 \%$ within a few hours, consistent with an $\mathrm{O}^{+}$proportion of $7-21 \% \mathrm{O}^{+}$by number. Knowledge of the electron number density and $\mathrm{He}^{+}$ concentration allows the plasma composition to be estimated.

(vii) Reversals of phase with time and frequency in crossphase spectra identify the presence of steep density gradients at the plasmapause, at drainage plumes, biteouts and other structures. This was confirmed by reference to in situ electron density data and EUV images.

(viii) We used a 2-D numerical MHD model incorporating realistic ionosphere boundary conditions and a magnetospheric Alfvén speed profile based on in situ measurements, to simulate the frequency and phase profiles expected across a ground station array at times when cross-phase reversals and steep density gradients were observed. This was able to reproduce the observations and provides information on how such cross-phase signatures are formed. This novel 
approach confirms the ability to model wave propagation and coupling to resonances near the plasmapause under realistic situations.

Acknowledgements. We thank all those involved in operating and providing data for the various instrument arrays. The IMAGE magnetometer array is operated by a multinational consortium headed by the Finnish Meteorological Institute, while SAMNET is operated by the Space Plasma Environment and Radio Science (SPEARS) group, Department of Physics, Lancaster University. The MEASURE magnetometer array is operated by Florida Institute of Technology and UCLA IGPP; the PI is M. Moldwin. Vernadksy magnetometer data were kindly supplied by G. Milinevski from the Ukranian Antarctic Center, while Rothera magnetometer and VLF data were obtained under the auspices of the NERC Antarctic Funding Initiative with logistic support from the British Antarctic Survey. RPI electron density data were supplied by Richard Denton, Phillip Webb, Jerry Goldstein, Jillian Redfern and Bodo Reinisch. IMAGE satellite EUV data were supplied by B. Sandel via the EUV web site at Arizona University. TEC tomographic data were kindly provided by E. Yizengaw of Boston College, having been obtained from the FedSat satellite developed and operated by the CRC for Satellite Systems under the Commonwealth of Australia Cooperative Research Centers Program. Aspects of this work were supported by the Australian Research Council through project no. DP0559544. FWM thanks the hospitality of the Department of Electronic Engineering at La Trobe University, Melbourne, during preparation of this report. The editor thanks Mark B. Moldwin and one anonymous referee for their assistance in evaluating this paper.

\section{References}

\section{References}

Abe, S., H. Kawano, J. Goldstein, S. Ohtani, S.I. Solovyev, D.G. Baishev, and K. Yumoto. Simultaneous identification of a plasmaspheric plume by a ground magnetometer pair and IMAGE extreme ultraviolet imager, J. Geophys. Res., 111, A11202, 2006, DOI: 10.1029/2006JA011653.

Benson, R.F., P.A. Webb, J.L. Green, L. Garcia, and B.W. Reinisch. Magnetospheric electron densities inferred from upper-hybrid band emissions, Geophys. Res. Lett., 31, L20803, 2004, DOI: 10.1029/2004GL020847.

Berube, D., M.B. Moldwin, and J.M. Weygand. An automated method for the detection of field line resonance frequencies using ground magnetometer techniques, J. Geophys. Res., 108, A9, 2003, DOI: 10.1029/2002JA009737.

Berube, D., M.B. Moldwin, S.F. Fung, and J.L. Green. A plasmaspheric mass density model and constraints on its heavy ion concentration, J. Geophys. Res., 110, A04212, 2005, DOI: 10.1029/2004JA010684.

Berube, D., M.B. Moldwin, and M. Ahn. Computing magnetospheric mass density from field line resonances in a realistic magnetic field geometry, J. Geophys. Res., 111, A08206, 2006, DOI: 10.1029/2005JA011450.

Burch, J.L. The first two years of IMAGE, Space Sci. Rev., 109, 1-4, 2003, DOI: 10.1023/B:SPAC.0000007510.32068.68.

Carpenter, D.L. Whistler evidence of a "knee" in the magnetospheric ionization density profile, J. Geophys. Res., 68 (6), 1675-1682, 1963, DOI: 10.1029/JZ068i006p01675.

Carpenter, D.L., and C.G. Park. On what ionospheric workers should know about the plasmapause-plasmasphere, Rev. Geophys. Space Phys., 11 (1), 133-154, 1973,

DOI: 10.1029/RG011i001p00133.
Carpenter, D.L., and R.R. Anderson. An ISEE/whistler model of equatorial electron density in the magnetosphere, J. Geophys. Res., 97, A2, 1097-1108, 1992, DOI: 10.1029/91JA01548.

Carpenter, D.L., R.R. Anderson, W. Calvert, and M.B. Moldwin. CRRES observations of density cavities inside the plasmasphere, J. Geophys. Res., 105, 23323-23338, 2000,

DOI: 10.1029/2000JA000013.

Chappell, C.R., K.K. Harris, and G.W. Sharp. The dayside of the plasmasphere, J. Geophys. Res., 76 (31), 7632-7647, 1971, DOI: 10.1029/JA076i031p07632.

Chi, P.J., C.T. Russell, S. Musman, W.K. Peterson, G. Le, V. Angelopolous, G.D. Reeves, M.B. Moldwin, and F.K. Chun. Plasmaspheric depletion and refilling associated with the September 25, 1978 magnetic storm observed by ground magnetometers at $L=2$, Geophys. Res. Lett., 27, 5, 2000, DOI: 10.1029/1999GL010722.

Chi, P.J., M.J. Engebretson, M.B. Moldwin, C.T. Russell, I.R. Mann, et al. Sounding of the plasmasphere by Mid-continent MAgnetoseismic Chain (McMAC) magnetometers, J. Geophys. Res., 118, 6, 2013, DOI: 10.1002/jgra.50274.

Clilverd, M.A., A.J. Smith, and N.R. Thomson. The annual variation in quiet time plasmaspheric electron density determined from whistler mode group delays, Planet. Space Sci., 39 (7), 1059-1067, 1991, DOI: 10.1016/0032-0633(91)90113-O.

Clilverd, M.A., F.W. Menk, G. Milinevski, B.R. Sandel, and J. Goldstein. In situ and ground-based intercalibration measurements of plasma density at $L=2.5, J$. Geophys. Res., 108, A10, 2003, DOI: 10.1029/2003JA009866.

Collier, A.B., J. Lichtenberger, M.A. Clilverd, C.J. Rodger, and P. Steinbach. Source region for whistlers detected at Rothera, Antarctica, J. Geophys. Res., 116, A03219, 2011,

DOI: $10.1029 / 2010 J A 016197$.

Daglis, I.A., R.M. Thorne, W. Baumjohann, and S. Orsino. The terrestrial ring current: origin, formation, and decay, Rev. Geophys., 37 (4), 407-438, 1999, DOI: 10.1.1.40.2177.

Darrouzet, F., P.M.E. Décréau, J. De Keyser, A. Masson, and D.L. Gallagher. Density structures inside the plasmasphere: cluster observations, Ann. Geophys., 22, 2577-2585, 2004, DOI: 10.5194/angeo-22-2577-2004.

Darrouzet, F., J. De Keyser, P.M.E. Décréau, D.L. Gallagher, V. Pierrad, et al. Analysis of plasmaspheric plumes: CLUSTER and IMAGE observations, Ann. Geophys., 24, 1737-1758, 2006, DOI: 10.5194/angeo-24-1737-2006.

Darrouzet, F., V. Pierrard, S. Benck, G. Lointier, and J. Cabrera. Links between the plasmapause and the radiation belt boundaries as observed by the instruments CIS, RAPID, and WHISPER onboard Cluster, J. Geophys. Res., 118, 7, 2013, DOI: 1.1002 /jgra.50239.

Denton, R.E., P.M.E. Décréau, M.J. Engebretson, F. Darrouzet, and J.L. Posch. Field line distribution of density at $\mathrm{L}=4.8$ inferred from observations by CLUSTER, Ann. Geophys, 27, 705-724, 2009, DOI: 10.5194/angeo-27-705-2009.

Foster, J.C., C.G. Park, L.H. Brace, J.R. Burrows, J.H. Hoffman, E.J. Maier, and J.H. Whitteker. Plasmapause signatures in the ionosphere and magnetosphere, J. Geophys. Res., 83, A3, 1175-1182, 1978, DOI: 10.1029/JA083iA03p01175.

Foster, J.C., P.J. Erickson, A.J. Coster, J. Goldstein, and F.J. Rich. Ionospheric signatures of plasmaspheric tails, Geophys. Res. Lett., 29, 13, 2002, DOI: 10.1029/2002GL015067.

Fraser, B.J. The FedSat microsatellite mission, Space Sci. Rev., 107, 1-2, 2003, DOI: 10.1023/A:1025508816225.

Fraser, B.J., J.L. Horwitz, J.A. Slavin, Z.C. Dent, and I.R. Mann. Heavy ion mass loading of the geomagnetic field near the plasmapause and ULF wave implications, Geophys. Res. Lett., 32, L04102, 2005, DOI: 10.1029/2004GL021315.

Gallagher, D.L., P.D. Craven, and R.H. Comfort. Global core plasma model, J. Geophys. Res., 105, A8, 18819-18833, 2000, DOI: 10.1029/1999JA000241. 
Gjerloev, J.W. The SuperMAG data processing technique, J. Geophys. Res., 117, A9, 1978-2012, 2012,

DOI: $10.1029 / 2012 J A 017683$.

Goldstein, J., and B.R. Sandel. The global pattern of evolution of plasmaspheric drainage plumes. In: J. Burch, M. Schulz, and $\mathrm{H}$. Spence, Editor, Inner magnetosphere interactions: new perspectives from imaging. American Geophysical Union, Washington, D.C., 2005, DOI: 10.1029/159GM02.

Goldstein, J., R.W. Spiro, P.H. Reiff, R.A. Wolf, and B.R. Sandel. IMF-driven overshielding electric field and the origin of the plasmaspheric shoulder of March 24, 2000, Geophys. Res. Lett, 29, 16, 2002, DOI: 10.1029/2001GL014534.

Goldstein, J., M. Spasojević, P.H. Reiff, B.R. Sandel, T. Forrester, D.L. Gallagher, and B.W. Reinisch. Identifying the plasmapause in IMAGE EUV data using IMAGE RPI in situ steep density gradients, J. Geophys. Res., 108, A4, 2003, DOI: $10.1029 / 2002 J A 009475$.

Grew, R.S., F.W. Menk, M.A. Clilverd, and B.R. Sandel. Mass and electron densities in the inner magnetosphere during a prolonged disturbed interval, Geophys. Res. Lett, 34, L02108, 2007, DOI: 10.1029/2006GL028254.

Hartinger, M., M.B. Moldwin, V. Angelopolous, K. Takahashi, H.J. Singer, R.R. Anderson, Y. Nishimura, and J.R. Wygant. Pc5 wave power in the quiet-time plasmasphere and trough: CRRES observations, Geophys. Res. Lett., 37, L07107, 2010, DOI: 10.1029/2010GL042475.

Horwitz, J.L., R.H. Comfort, and C.R. Chappell. A statistical characterization of plasmapshere density structure and boundary locations, J. Geophys. Res., 95, 7937-7947, 1990,

DOI: 10.1029/JA095iA06p07937.

Kabin, K., R. Rankin, I.R. Mann, A.W. Degeling, and R. Marchand. Polarization properties of standing shear Alfvén waves in nonaxisymmetric background magnetic fields, Ann. Geophys., 25, 815-822, 2007, DOI: 10.5194/angeo-25-815-2007.

Kale, Z.C., I.R. Mann, C.L. Waters, J. Goldstein, F.W. Menk, and L.G. Ozeke. Ground magnetometer observation of a cross-phase reversal at a steep plasmapause, J. Geophys. Res., 112, A10222, 2007, DOI: $10.1029 / 2007$ JA012367.

Kale, Z.C., I.R. Mann, C.L. Waters, M. Vellante, T.L. Zhang, and F. Honary. Plasmaspheric dynamics resulting from the Hallowe'en 2003 geomagnetic storms, J. Geophys. Res., 114, A08204, 2009, DOI: $10.1029 / 2009 J A 014194$.

Kim, K.-H., J. Goldstein, and D. Berube. Plasmaspheric drainage plume observed by the Polar satellite in the prenoon sector and the IMAGE satellite during the magnetic storm of 11 April 2001, J. Geophys. Res., 112, A06237, 2007, DOI: 10.1029/2006JA012030.

Lichtenberger, J., M.A. Clilverd, B. Heilig, M. Vellante, and J Manninen. The plasmasphere during a space weather event: first results from the PLASMON project, J. Space Weather Space Clim., 3, A23, 2013, DOI: 10.1051/swsc/2013045.

Menk, F.W., and C.L. Waters. Magnetoseismology: ground-based remote sensing of Earth's magnetosphere, Wiley, Berlin, 2013.

Menk, F.W., D. Orr, M.A. Clilverd, A.J. Smith, C.L. Waters, D.K. Milling, and B.J. Fraser. Monitoring spatial and temporal variations in the dayside plasmasphere using geomagnetic field line resonances, J. Geophys. Res., 104, A9, 19955-19969, 1999, DOI: $10.1029 / 1999 J A 900205$.

Menk, F.W., I.R. Mann, A.J. Smith, C.L. Waters, M.A. Clilverd, and D.K. Milling. Monitoring the plasmapause using geomagnetic field line resonances, J. Geophys. Res., 109, A04216, 2004, DOI: $10.1029 / 2003 J A 010097$.

Menk, F.W., S.T. Ables, R.S. Grew, M.A. Clilverd, and B.R. Sandel. The annual and longitudinal variations in plasmaspheric ion density, J. Geophys. Res., 117, A3, 2012, DOI: $10.1029 / 2011 \mathrm{JA} 017071$.

Milling, D.K., I.R. Mann, and F.W. Menk. Diagnosing the plasmapause with a network of closely spaced ground-based magnetometers, Geophys. Res. Lett., 28 (1), 115-118, 2001, DOI: $10.1029 / 2000$ GL011935.
Moldwin, M.B., L. Downward, H.K. Rassoul, R. Amin, and R.R. Anderson. A new model of the location of the plasmapause: CRRES results, J. Geophys. Res., 107, A11, 2002, DOI: $10.1029 / 2001 J A 009211$

Moldwin, M.B., J. Howard, J. Sanny, J.D. Bocchicchio, H.K. Rassoul, and R.R. Anderson. Plasmaspheric plumes: CRRES observations of enhanced density beyond the plasmapause, J. Geophys. Res., 109, A5, 2004, DOI: $10.1029 / 2003 J A 010320$.

Moore, T.E., D.L. Gallagher, J.L. Horwitz, and R.H. Comfort. MHD wave breaking in the outer plasmasphere, Geophys. Res. Lett., 14, 10, 1987, DOI: 10.1029/GL014i010p01007.

Morley, S.K., S.T. Ables, M.D. Sciffer, and B.J. Fraser. Multipoint observations of Pc1-2 waves in the afternoon sector, J. Geophys. Res., 114, A09205, 2009, DOI: 10.1029/2009JA014162.

Obana, Y., F.W. Menk, M.D. Sciffer, and C.L. Waters. Quarter-wave modes of standing Alfvén waves detected by cross-phase analysis, J. Geophys. Res., 113, A08203, 2008, DOI: $10.1029 / 2007$ JA012917.

Obana, Y., F.W. Menk, and I. Yoshikawa. Plasma refilling rates for $L=2.3-3.8$ flux tubes, J. Geophys. Res., 115, A03204, 2010, DOI: 10.1029/2009JA014191.

O'Brien, T.P., and M.B. Moldwin. Empirical plasmapause models from magnetic indices, Geophys. Res. Lett., 30 (4), 1152, 2003, DOI: 10.1029/2002GL016007.

Ozhogin, P., J. Tu, P. Song, and B.W. Reinisch. Field-aligned distribution of the plasmaspheric electron density: an empirical model derived from the IMAGE RPI measurements, J. Geophys. Res., 117, A06225, 2012, DOI: 10.1029/2011JA017330.

Park, C.G., D.L. Carpenter, and D.B. Wiggin. Electron density in the plasmasphere: whistler data on solar cycle, annual and diurnal variations, J. Geophys. Res., 83, A7, 1978, DOI: 10.1029/JA083iA07p03137.

Poulter, E.M., and W. Allan. The ground magnetic fields of transient ULF pulsations at the plasmapause, Planet. Space Sci., 34 (11), 1073-1079, 1986.

Reinisch, B.W., X. Huang, D.M. Haines, I.A. Galkin, and J.L. Green. First results from the Radio Plasma Imager on IMAGE, Geophys. Res. Lett., 28, 6, 2001, DOI: 10.1029/2000GL012398.

Reinisch, B.W., X. Huang, P. Song, J.L. Green, S.F. Fung, V.M. Vasyliunas, D.L. Gallagher, and B.R. Sandel. Plasmaspheric mass loss and refilling as a result of a magnetic storm, J. Geophys. Res., 109, A01202, 2004, DOI: 10.1029/2003JA009948.

Saka, O., and J.S. Kim. Spatial phase structure of low-latitude Pc3-4 pulsations, Planet. Space Sci., 33 (9), 1073-1079, 1985.

Sandel, B.R., J. Goldstein, D.L. Gallagher, and M. Spasojevic. Extreme ultraviolet imager observations of the structure and dynamics of the plasmasphere, Space Sci. Rev., 109, 1-4, 2003, DOI: 10.1023/B:SPAC.0000007511.47727.5b.

Singh, N., and J.L. Horwitz. Plasmasphere refilling: recent observations and modelling, J. Geophys. Res., 97, A2, 1992, DOI: 10.1029/91JA02602.

Spasojević, M., J. Goldstein, D.L. Carpenter, U.S. Inan, B.R. Sandel, M.B. Moldwin, and B.W. Reinisch. Global response of the plasmasphere to a geomagnetic disturbance, J. Geophys. Res., 108, A9, 2003, DOI: 10.1029/2003JA009987.

Summers, D., B. Li, and N.P. Meredith. Timescales for radiation belt electron acceleration and loss due to resonant wave-particle interactions: 2. Evaluation for VLF chorus, ELF hiss, and electromagnetic ion cyclotron waves, J. Geophys. Res., 112, A04207, 2007, DOI: 101.209/2006JA011993.

Takahashi, K., R.E. Denton, R.R. Anderson, and W.J. Hughes. Mass density inferred from toroidal wave frequencies and its comparison to electron density, J. Geophys. Res., 111, A01201, 2006, DOI: 10.1029/2005JA011286.

Takahashi, K., S.-I. Ohtani, R.E. Denton, W.J. Hughes, and R.R. Anderson. Ion composition in the plasma trough and plasma plume derived from a Combined Release and Radiation Effects Satellite magnetoseismic study, J. Geophys. Res., 113, A12203, 2008, DOI: 10.1029/2008JA013248. 
Vellante, M., and M. Föster. Inference of the magnetospheric plasma mass density from field line resonances: a test using a plasmasphere model, J. Geophys. Res., 111, A11204, 2006, DOI: $10.1029 / 2005 J A 011588$.

Walker, A.D.M. Formation of whistler ducts, Planet. Space Sci., 26 (4), 375-379, 1978, DOI: 10.1016/0032-0633(78)90121-6.

Waters, C.L., and M.D. Sciffer. Field line resonant frequencies and ionospheric conductance: results from a 2-D MHD model, J. Geophys. Res., 113, A05219, 2008, DOI: $10.1029 / 2007 J A 012822$

Waters, C.L., F.W. Menk, and B.J. Fraser. The resonance structure of low latitude Pc3 geomagnetic pulsations, Geophys. Res. Lett., 18 (12), 2293-2296, 1991, DOI: 10.1029/91GL02550.

Waters, C.L., B.G. Harrold, F.W. Menk, J.C. Samson, and B.J. Fraser. Field line resonances and waveguide modes at low latitudes, 2. A model, J. Geophys. Res., 105, A4, 7763-7774, 2000, DOI: 10.1029/1999JA900267.

Waters, C.L., F.W. Menk, M.F. Thomson, C. Foster, and F.R. Fenrich. Remote sensing the magnetosphere using groundbased observations of ULF waves. In: K. Takahashi, P.J. Chi, R.E. Denton, and R.L. Lysak, Editors, Magnetospheric ULF waves: synthesis and new directions. American Geophysical Union, Washington, DC, 319-340, 2006, DOI: $10.1029 / 169 \mathrm{GM} 21$

Waters, C.L., J.C. Samson, and E.F. Donovan. The temporal variation of the frequency of high latitude field line resonances, J. Geophys. Res., 100, A5, 7987-7996, 1995, DOI: $10.1029 / 94 J A 02712$.
Yizengaw, E., and M.B. Moldwin. The altitude extension of the mid-latitude trough and its correlation with plasmapause position, Geophys. Res. Lett., 32, L09105, 2005, DOI: 10.1029/2005GL022854.

Yizengaw, E., M.B. Moldwin, P.L. Dyson, B.J. Fraser, and S. Morley. First tomographic image of ionospheric outflows, Geophys. Res. Lett., 33, L20102, 2006a, DOI: 10.1029/2006GL027698.

Yizengaw, E., M.B. Moldwin, and D.A. Galvan. Ionospheric signatures of a plasmaspheric plume over Europe, Geophys. Res. Lett., 33, L17103, 2006b, DOI: 10.1029/2006GL026597.

Yizengaw, E., J. Dewar, J. MacNeil, M.B. Moldwin, D. Galvan, J. Sanny, D. Berube, and B. Sandel. The occurrence of ionospheric signatures of plasmaspheric plumes over different longitudinal sectors, J. Geophys. Res., 113, A08318, 2008, DOI: $10.1029 / 2007$ JA012925.

Yoshikawa, I., A. Yamazaki, K. Shiomi, K. Yamashita, Y. Takizawa, and M. Nakamura. Evolution of the outer plasmasphere during low geomagnetic activity observed by the EUV scanner onboard Planet-B, J. Geophys. Res., 105, A12, 27777-27789, 2000, DOI: $10.1029 / 2000 J A 900106$.

Zhang, X., R.H. Comfort, Z.E. Musielak, T.E. Moore, D.L. Gallagher, and J.L. Green. Propagation characteristics of Pc3 compressional waves generated at the dayside magnetopause, J. Geophys. Res., 98, A9, 15403-15410, 1993, DOI: $10.1029 / 93 \mathrm{JA} 01322$.

Cite this article as: Menk F., Z. Kale, M. Sciffer, P. Robinson, C. Waters, et al.: Remote sensing the plasmasphere, plasmapause, plumes and other features using ground-based magnetometers. J. Space Weather Space Clim., 4, A34, 2014, DOI: 10.1051/swsc/2014030. 